\title{
The nesting ecology, habitat preference, abundance and impacts of Polistes dominula in New Zealand
}

\author{
by
}

Rose McGruddy

A thesis submitted to Victoria University of Wellington in part fulfilment of the requirements for a degree of Master of Science in Ecology and Biodiversity

Victoria University of Wellington

Te Herenga Waka 2021 


\section{General abstract}

Introduced wasps can have significant impacts on communities within their newly invaded range. A recent wasp introduction to New Zealand is the European paper wasp, Polistes dominula Christ, which was first observed in the Nelson-Tasman region in 2016. The ecology and behaviour of $P$. dominula was investigated, as well as the direct and indirect impacts of this wasp on local communities in Nelson. Aspects of nesting behaviour, habitat preference and abundance were studied with the intent to inform management decisions. The abundance and colony survival of $P$. dominula was greatest in suburban areas, where nests were predominantly built within anthropogenic structures. Colony survival of $P$. dominula was comparatively higher than for colonies of the longer established exotic congener Polistes chinensis Pérez. Neither Polistes species were found to nest within native or exotic forest sites, with translocated colonies of $P$. dominula unsuccessful within forest habitats. As a species that originates from a warmer climate, the lower temperatures in forests are likely a contributor to the inability of $P$. dominula to thrive in these areas.

The impacts that newly invasive predators have on communities within their invaded range are often poorly understood. Following the arrival of $P$. dominula, I show data indicating that there have been substantial declines in the abundance of several local butterfly species in Nelson. The monarch butterfly, Danaus plexippus Linnaeus was one of the species reported by residents to be in population decline. Field experiments found $P$. dominula to be a major cause of monarch caterpillar mortality. Caterpillar survival was the lowest in suburban areas, where the abundance of $P$. dominula was highest. Early instar caterpillars had comparatively higher mortality rates than late instar caterpillars, as the defensive behaviour of larger caterpillars had greater success against these wasps. Whilst $P$. dominula was the main driver behind caterpillar mortality throughout my experiments, the discovery of caterpillars by wasps appeared to happen by chance through direct contact between the wasp and their prey. There was also no evidence of nestmate recruitment by foraging wasps to sites where caterpillars were found.

Predation has the capacity to not only impact prey populations, but through the suppression of herbivory, plants can indirectly benefit from the presence of predators. The presence of $P$. dominula was found to have strong, cascading effects on the 
milkweed host and food plant of $D$. plexippus. Milkweed fitness in areas populated by $P$. dominula was substantially greater than the fitness of plants in areas without this invasive predator. Plant growth and reproduction of milkweeds placed in areas where $P$. dominula were present, and able to predate upon caterpillars, were found to exhibit a similar amount of growth and flower production as netted control plants which excluded monarch caterpillars completely. The outcomes of this experiment suggest that $P$. dominula is strongly suppressing these herbivorous caterpillars.

Overall, this thesis provides insight into the behaviour and ecology of $P$. dominula in New Zealand. Findings of this research suggest that this newly invasive wasp is having detrimental effects on local communities and that $P$. dominula should be controlled to reduce the impacts of this wasp on New Zealand's ecosystems. Knowledge obtained in this study can direct conservation management strategies and aid in the development of effective control methods. 


\section{Acknowledgements}

Firstly, I would like to thank Phil Lester for his support and patience during this postgraduate research. I would also like to thank Richard Toft from Entecol for his assistance with the research conducted in Nelson and allowing us to use his lab and equipment over the two summers.

I am grateful to Matthew Howse for his collaboration and assistance throughout this whole project, both in the field and during the writing of this thesis.

Thanks goes out to the Lester Lab group: John Haywood, Jana Dobelmann, Mariana Bulgarella, Antoine Felden and James Baty, who have all contributed useful and constructive advice during our meetings and for answering my pesky questions. I have learned a lot from these people and their support has been greatly appreciated. Special thanks to John Haywood, who spent hours giving valuable statistical advice and provided helpful comments on chapter three.

I thank the residents of Nelson for their participation and hospitality. Their assistance throughout this project, from allowing us onto their properties each week to monitor nests, to watering swan plants, to providing monarch caterpillars, to providing welcome refreshment on hot days, was invaluable.

I would like to thank Victoria University of Wellington for their financial support.

Finally, I would like to thank the couch crew, friends and family for their support throughout this process. 


\section{Table of contents}

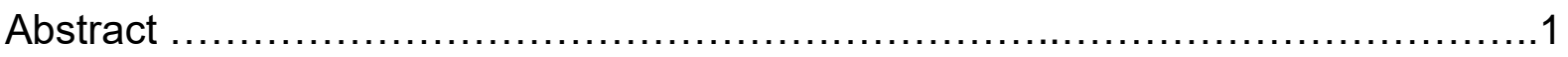

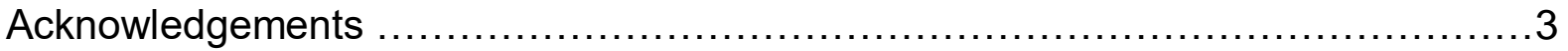

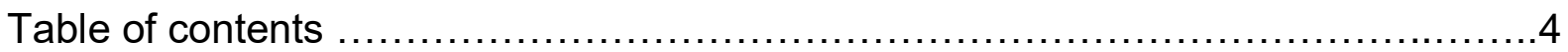

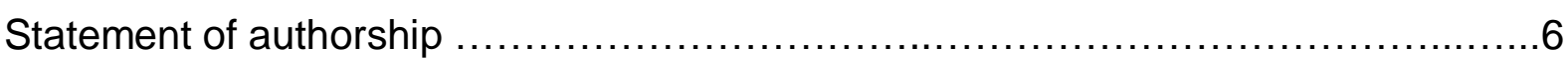

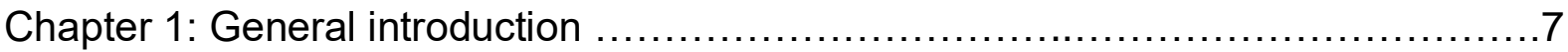

Chapter 2: Nesting ecology and colony survival of two invasive Polistes wasps (Hymenoptera: Vespidae) in New Zealand .........................................11

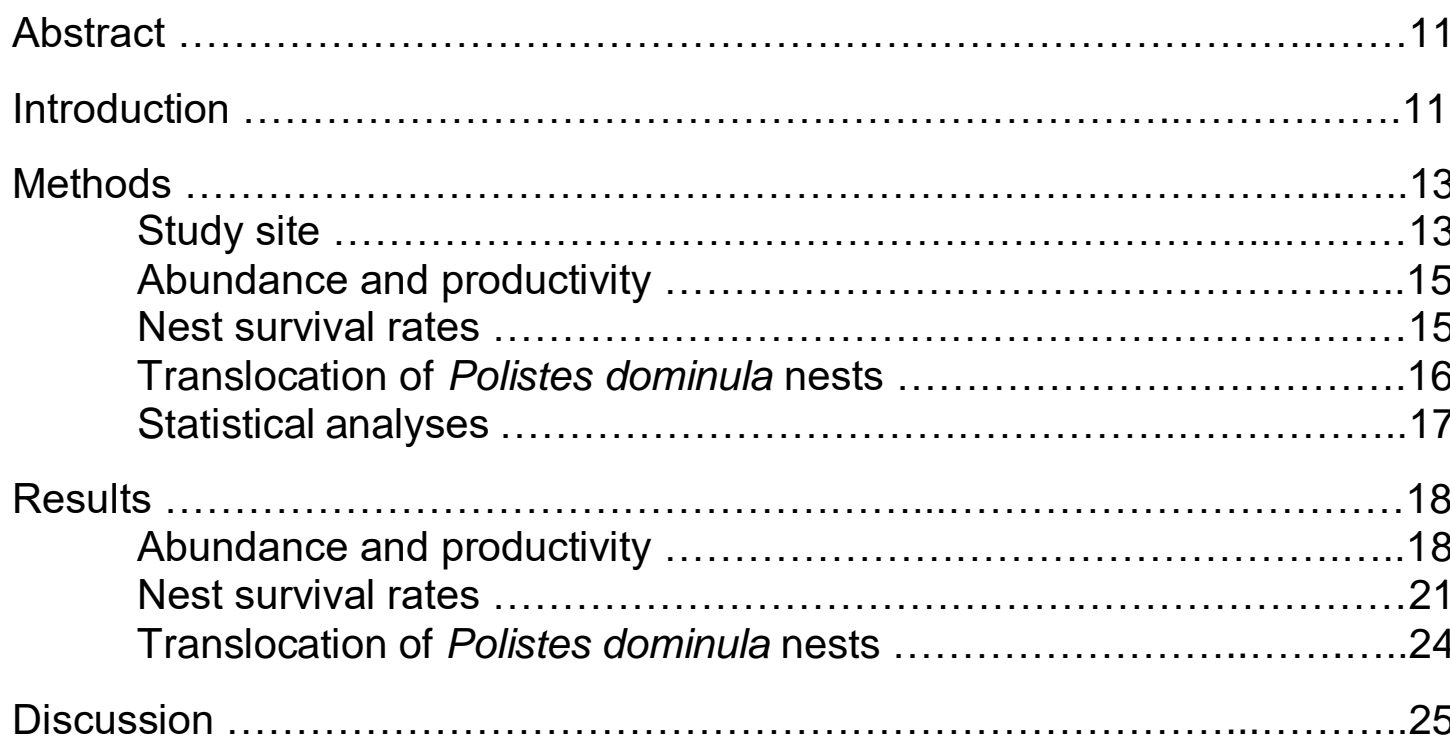

Chapter 3: Invasive paper wasps have strong cascading effects on the host plant of

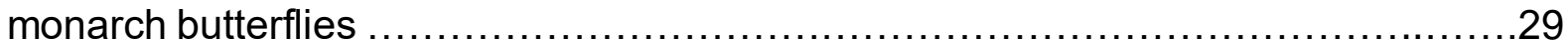

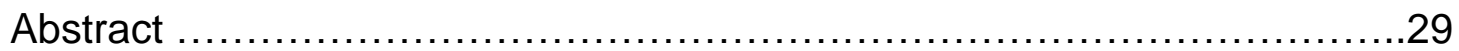

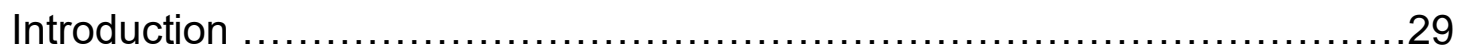

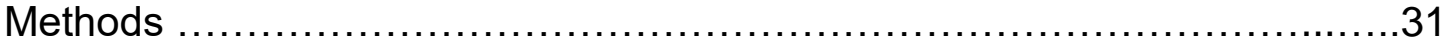

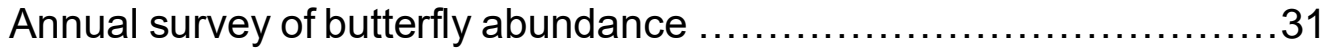

Predation of caterpillars by Polistes dominula ..........................32

Cascading effects of Polistes dominula predation .......................35

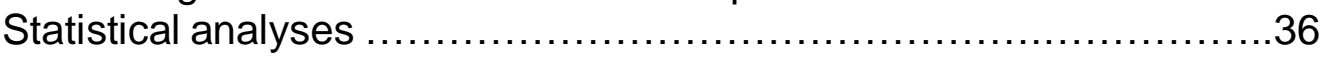

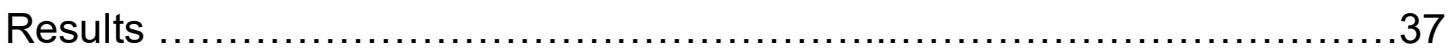

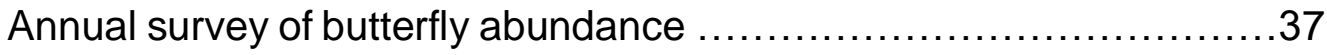

Predation of caterpillars by Polistes dominula ...........................39

Cascading effects of Polistes dominula predation .......................41

Discussion .......................................................................... 43

Chapter 4: General discussion ...................................................4

The abundance, nesting ecology and survival of Polistes dominula ............47

The direct impacts of Polistes dominula ........................................49 
The cascading effects of Polistes dominula ......................................49

Future directions and management of Polistes dominula .......................50

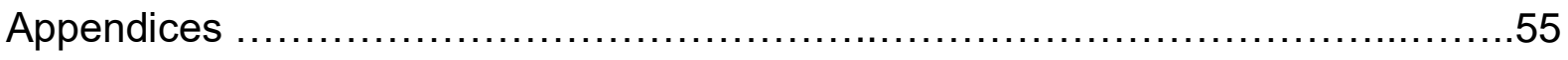

Appendix A: Nest substrates of Polistes spp. and additional data regarding the nest translocation experiment for chapter two...................................55 Appendix B: Climatic data for annual butterfly survey and wasp abundance for

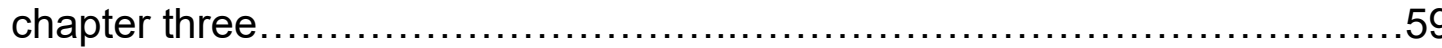

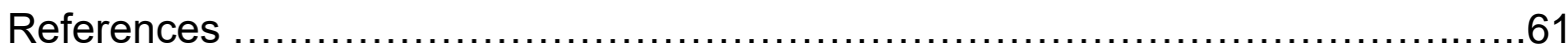




\section{Statement of authorship}

I hereby declare that this thesis is my own work and that all sources paraphrased or referred to have been properly acknowledged in the references.

Chapter 2 author contributions: R.A.M. formulated the research questions and wrote the manuscript. R.A.M. and M.W.F.H. conducted the research with R.T. providing guidance and assistance. R.A.M. and J.H. analysed the results. P.J.L. provided comments on draft versions of the manuscript.

Chapter 3 was published in Ecological Entomology in December 2020. Author contributions: R.A.M. designed the experiments, analysed the data, and wrote the draft manuscript, R.A.M., M.W.F.H., C.J.I.W., and T.B.S. collected the data, J.H. aided in interpreting the results and advised on statistical analyses, plus edited the manuscript, M.H-W. compiled the data for the annual butterfly survey, P.J.L. and R.J.T. assisted with conceptualisation, supervised the work and contributed to the final manuscript.

1 Author initials and names: R.A.M. Rose McGruddy, M.W.F.H. Matthew Howse, C.J.I.W. Chrissie Ward, T.B.S. Tony Staufer, J.H. John Haywood, M.H-W. Mary Hayek-Williams, P.J.L. Phil Lester, R.J.T. Richard Toft. 


\section{Chapter 1: General Introduction}

Biological invasions threaten biodiversity and disrupt ecosystem processes worldwide (Pysek et al., 2020; Pysek \& Richardson, 2010; Spatz et al., 2017). Through their direct and indirect effects, invasive species can significantly alter ecosystems (O'Dowd et al., 2003; Pysek et al., 2020). The ecological and economic consequences of biological invasions have been well documented in the literature (Snyder et al., 2004; Vilà et al., 2011), with invasive species described as a leading contributor to species endangerment and extinction (Paolucci et al., 2013; Pilowsky \& Starks, 2018). Increased global connectivity has accelerated the rates of species introductions, which is further exacerbated by global change (Paini et al., 2016; Pysek et al., 2020; Renault et al., 2018). Research into the ecology of invasive species within their new range, their impacts on native communities and understanding the processes which allow for the successful establishment of a species, is essential for devising effective management strategies (Beggs et al., 2011; Caesar, 2005; Nuñez et al., 2017).

Hymenopteran insects have proven themselves to be exceptionally successful invaders globally (Beggs et al., 2011; Lester \& Beggs, 2019; Tsutsui \& Suarez, 2003). Social invasive insects are particularly successful as a result of their ability to reach high densities, their social behaviour, and wide-ranging, generalist diets (Lester \& Beggs, 2019; Ward \& Morgan, 2014). In their native range, generalist insect predators play important roles in terrestrial food webs, as they feed across a range of trophic levels (Crowder \& Snyder, 2010). Predators therefore have the potential to structure communities and alter species diversity (Beschta \& Ripple, 2009). However, invasive predators can have devastating impacts on native communities (Beggs \& Rees, 1999; Potter-Craven et al., 2018; Toft \& Rees, 1998) due to prey sharing no ecological or evolutionary history with the invader (Salo et al., 2007). Invasive social insects have been found to drive shifts in ecosystems directly via predation and indirectly through cascading effects across trophic levels (Moya-Laraño \& Wise, 2007; O'Dowd et al., 2003). Predatory wasps have demonstrated an ability to alter communities within their invaded range, which has been credited to their colony productivity and high nest densities (Beggs et al., 2011; Lester \& Beggs, 2019). The success and colony productivity of social wasps is dependent on environmental and ecological factors, which can vary across their native and invaded ranges (Clapperton \& Dymock, 1997; 
Roets et al., 2019). Therefore, understanding the ecology of newly invasive wasps is crucial, as the nesting behaviour, abundance and impacts of these predators can vary greatly between regions (Hozumi et al., 2015; Lester \& Beggs, 2019; Sheehan et al., 2015).

Islands often contain a large proportion of unique, endemic species due to their geographic isolation from the mainland (Paulay, 1994; Reaser et al., 2007). This distance can limit the taxa of organisms that can naturally colonise these islands. Populations of species are often smaller on islands relative to the mainland as a result of the smaller land area. Smaller population sizes make island biota more sensitive to ecological disturbance and species extinction (Reaser et al., 2007). The vulnerability of island ecosystems to the threat of invasive species is now widely acknowledged (Donlan \& Wilcox, 2008; Spatz et al., 2017). New Zealand broke away from the mainland 80 million years ago (Waters \& Craw, 2006), and as a result of its long isolation, evolved a large proportion of endemic species (Wilson, 1997). Many native species have been lost since the arrival of humans and the associated introduction, both deliberate and accidental, of exotic species (Cassey, 2001; Dowding \& Murphy, 2001). To conserve New Zealand's ecosystems and economy, biosecurity has become a national priority (Brenton-Rule et al., 2016; Pysek et al., 2020).

Like many other islands, New Zealand's invertebrates exhibit a high level of endemicity. For example, of the 2,000 native butterfly and moth species that have been identified, 90\% are endemic (Stringer \& Hitchmough, 2012). Introduced predators have impacted the populations of numerous invertebrate species across New Zealand (Stringer \& Hitchmough, 2012). Invertebrates are crucial in structuring ecosystems as primary consumers, predators, prey, pollinators and detritivores (Seastedt \& Crossley, 1984). Despite their importance, invertebrates are not often prioritised in conservation management (Clark \& May, 2002).

Native wasps in New Zealand are solitary, so native entomofauna are ill-equipped to tolerate the abundance and predation pressure of predatory social wasps. Two invasive wasps, Vespula germanica Fabricius and $V$. vulgaris Linnaeus have become particularly abundant in New Zealand, threatening biodiversity and ecosystem function (Beggs et al., 2011; Lester \& Beggs, 2019). The overall estimated cost of these wasps to the New Zealand economy is estimated to be greater than $\$ 130$ million per year 
(Maclntyre \& Hellstrom, 2015). Other invasive wasps that have successfully established include two paper wasp species, Polistes chinensis (subspecies: antennalis) Pérez and $P$. humilis Fabricius, who through predation or competition for food has impacted local biodiversity (Clapperton, 1999; Ward \& Ramón-Laca, 2013).

The European paper wasp, Polistes dominula Christ, is an invasive wasp whose presence in New Zealand was first realised in the summer of 2015, with estimates that this invader could have arrived as early as 2011 (MPI, 2016). The sunny Mediterranean area is the predominant native range of $P$. dominula. Like many other invasive species, $P$. dominula has moved from warmer to more temperate areas across several continents with the aid of human trade and travel (Benade et al., 2014; Cervo et al., 2000; Liebert et al., 2006; Weiner et al., 2011). This success of $P$. dominula as an invader has been attributed to its generalist diet, co-founding behavior, high colony survival rates and the use of anthropogenic structures as nesting sites (Roets et al., 2019; Tibbetts \& Reeve, 2003). Previous research has found $P$. dominula to primarily be an urban species, though it has been discovered in other habitat types (Gamboa et al., 2005; Roets et al., 2019). Polistes dominula consume carbohydratebased foods, such as nectar and fruit, to meet the energy requirements of the adults (Cranshaw et al., 2011). In addition to this, like many other Polistes spp., P. dominula are generalist predators, preying upon a variety of invertebrates, including many Lepidopteran species, to feed to their developing larvae (Cervo et al., 2000; Jeon et al., 2019; Ward \& Ramón-Laca, 2013).

This study was conducted to investigate the ecology and potential impacts of the invasive paper wasp Polistes dominula in New Zealand. Study sites were within the Nelson-Tasman area, as this is where $P$. dominula was first discovered and believed to have been the longest. I investigated the abundance and nesting ecology of this invasive wasp. I also assessed the predation pressure $P$. dominula exerted over prey and the indirect effects this wasp could have on plants.

In Chapter 2, I studied the abundance and ecology of $P$. dominula in comparison to the longer-established $P$. chinensis. I investigated the habitat preference, colony productivity and nest survival of both paper wasp species to inform decisions on the population management of $P$. dominula. 
In Chapter 3, I studied both the direct and indirect effects of $P$. dominula as a predator. $I$ investigated the predation pressure that $P$. dominula exerted on a local butterfly species, Danaus plexippus Linnaeus. The indirect, cascading effects of $P$. dominula on the host plant of $D$. plexippus were also tested.

Finally, in Chapter 4, I discuss the implications of my results. Overall, this thesis suggests that $P$. dominula is having an impact on local communities in New Zealand and provides some insight into the ecology of this invasive wasp which can inform management strategies. 


\title{
Chapter 2: Nesting ecology and colony survival of two invasive Polistes wasps (Hymenoptera: Vespidae) in New Zealand
}

\begin{abstract}
We examined the abundance, nesting ecology and colony survival of two invasive species of paper wasp, Polistes dominula Christ and Polistes chinensis Pérez (subspecies: antennalis), within their invaded range of New Zealand. The more recent invader of the two species, $P$. dominula, exhibited a strong habitat preference, reaching the highest abundances within suburban areas. Coastal habitats were also found to be suitable environments for $P$. dominula, although wasp abundance in these areas was comparatively lower in comparison to suburban sites. Whilst $P$. chinensis showed a preference for nesting in coastal habitats, this was not reflected in the abundance of adult wasps in these areas. Nests of $P$. dominula were larger and more productive, likely a result of the multiple founding and earlier emergence of workers compared to $P$. chinensis. Both species exhibited significant differences in nest survival, with $P$. dominula observed to have a higher colony survival rate, particularly in suburban habitats where this species utilized manmade substrates as nesting sites. Neither species nested within forest sites and translocated nests of $P$. dominula failed to thrive within forest habitats. Findings of this research suggest that $P$. dominula will not pose a threat to species inhabiting forested areas. Instead, biodiversity managers should focus their efforts on suburban and coastal environments as native species in these areas will require the greatest protection.
\end{abstract}

\section{Introduction}

Invasive species have adverse consequences for biodiversity and ecosystem processes (Pysek et al., 2020; Pysek \& Richardson, 2010; Spatz et al., 2017). Invasive social insects count amongst the most wide-ranging and destructive species (Lester \& Beggs, 2019; Pilowsky \& Starks, 2018). Social insects constitute a large portion of invasive invertebrate research due to their ability to reach high densities, often having 
a wide host range and feeding across a range of trophic levels (Roy et al., 2011; Snyder \& Evans, 2006; Ward \& Morgan, 2014). Social wasps can cause considerable ecological and economic damage in the ecosystems they invade (Beggs et al., 2011; Lester \& Beggs, 2019). Numerous factors contribute to the success of social wasps and colony productivity is arguably the most important (Perez-Bote et al., 2020). Productivity depends on both ecological and environmental factors.

The European paper wasp, Polistes dominula Christ and Asian paper wasp, Polistes chinensis Pérez (subspecies: antennalis), are two predatory social wasps that have recently established in New Zealand. The most recent invader of the two paper wasp species is $P$. dominula, whose presence in New Zealand was first realised in 2016, although it has been estimated that this wasp could have arrived as early as 2011 (MPI, 2016). The more widespread and established $P$. chinensis has been in New Zealand since the 1970s (Clapperton et al., 1996). Native wasps in New Zealand are predominantly solitary, so there are concerns about the impact these social wasp species could have on native communities. Research into the abundance and impact of $P$. chinensis has already been conducted in some parts of New Zealand (Clapperton et al., 1996; Clapperton \& Dymock, 1997; Clapperton \& Lo, 2000; Ward \& Morgan, 2014; Ward \& Ramón-Laca, 2013). As P. dominula is such a recent invader, little research has been conducted on this species in their newly invaded range. To help biodiversity managers, more information is needed on its habitat preference, colony growth, abundance and survival.

The native range of $P$. dominula is predominantly the Mediterranean region. With the assistance of human activity, this wasp has spread to other temperate areas across several continents (Benade et al., 2014; Cervo et al., 2000; Liebert et al., 2006). The success of $P$. dominula as an invader has largely been attributed to its generalist diet, comparatively short development time and co-founding behavior. Multiple studies investigating the success of $P$. dominula compared to native paper wasp species within its invaded range have found $P$. dominula to be the more successful species (Gamboa et al., 2004; Liebert et al., 2006; Pilowsky \& Starks, 2018; Roets et al., 2019). This success was often attributed to $P$. dominula being less parasitized, with higher nest survival rates and the utilization of human structures. Research within both the native and invaded range of this wasp found it to be a predominantly urban species, however, it has been observed in other habitats (Gamboa et al., 2005; Roets et al., 2019). 
Here, we compare nesting characteristics of the most recent invader $P$. dominula to the more established $P$. chinensis in New Zealand. We specifically compare these two species in terms of (1) habitat preference, (2) differences in seasonal activity phases, (3) differences in colony productivity (cell numbers in nests and wasp abundance), and (4) nest survival. An understanding of the nesting locations and abundance of $P$. dominula will allow biodiversity managers to predict the likely effects of this newly invaded wasp.

\section{Methods}

\section{Study Site}

This study was conducted in the Nelson-Tasman region of New Zealand $\left(41.299^{\circ} \mathrm{S}\right.$, $173.244^{\circ} \mathrm{E}$ ) (Fig. 2.1) over two reproductive cycles of the wasps, from late spring in November $19^{\text {th }}, 2018$ - early autumn in March $18^{\text {th }}, 2019$ and November $11^{\text {th }}, 2019-$ March $16^{\text {th }}, 2020$. Nelson is the site where $P$. dominula was first observed in New Zealand in 2016, and is believed to be the area where this wasp has been at the longest, although it is established in other areas of the upper part of the South Island and more recently there have been reports of $P$. dominula reaching more southern regions of the island. The only sightings of $P$. dominula in the North Island have been in Auckland. Temperature and precipitation in these areas appears to be favourable for $P$. dominula (Howse et al., 2020).

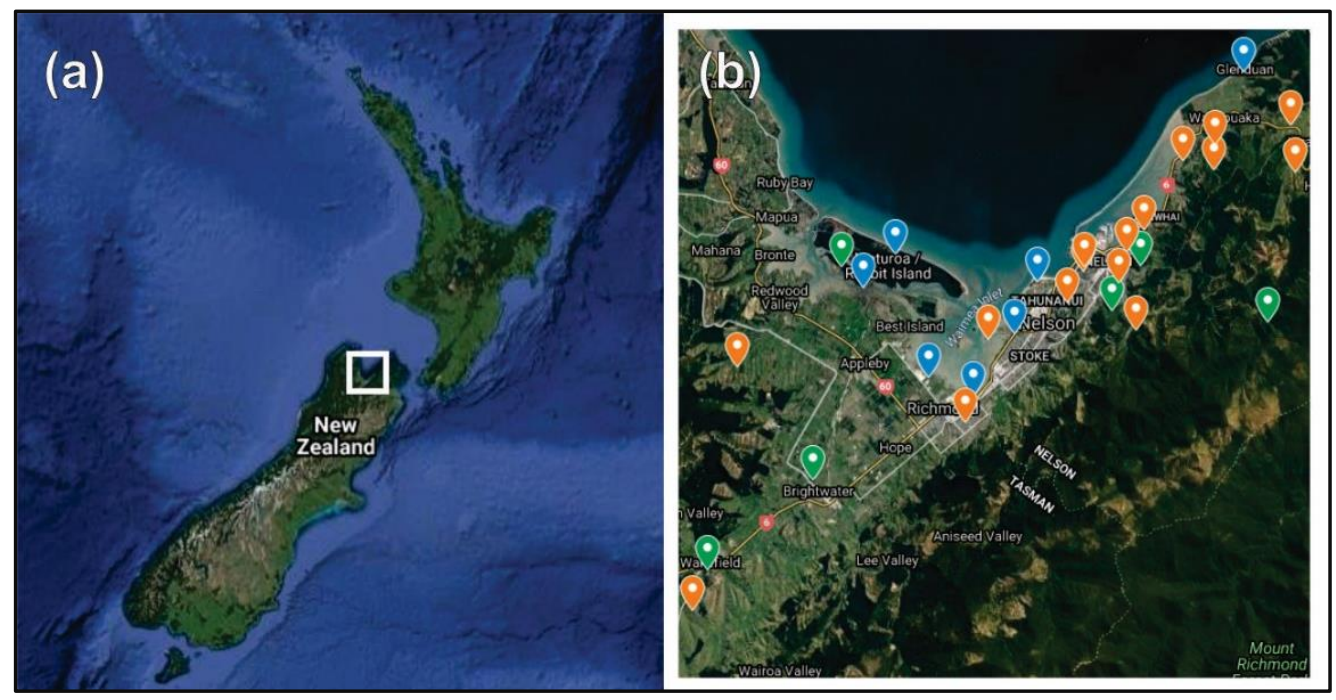

Fig. 2.1. (a) Map of New Zealand with the Nelson-Tasman region outlined by a white box and (b) study sites within the Nelson-Tasman region over the two summers of 2018/19 and 2019/20. Orange bookmarks represent suburban sites, blue bookmarks represent coastal sites and green bookmarks represent the forest sites. Sourced from google maps https://www.google.co.nz/maps 
To determine whether $P$. dominula and $P$. chinensis had a nesting preference, habitat was categorized into three types: suburban, coastal and forest (Fig. 2.2). Suburban sites were residential areas, each containing a house with a garden area. A total of 16 suburban sites were used over the two summers (Fig. 2.1b). Coastal sites shared at least one boundary within $100 \mathrm{~m}$ of the high tide line. A total of seven coastal sites were used over the two summers (Fig. 2.1b), which were comprised of a mix of shrubs, herbaceous plants, sedges and grasses. No permanent anthropogenic structures were present, however, some sites contained plant protectors as part of a conservation programme (Fig. 2.2a). These protectors were made of plastic, standing $40 \mathrm{~cm}$ tall, designed to protect plants from herbivory by rabbits and pukekos. Plant protectors were frequently used as nesting sites by both Polistes species. Forest sites had boundaries at least $50 \mathrm{~m}$ in from the forest edge and a minimum canopy cover of $50 \%$. There were six forest sites (Fig. 2.1b), which were classified as industrial pine, native beech, native podocarp, or a mix of regenerating native and exotic forest.

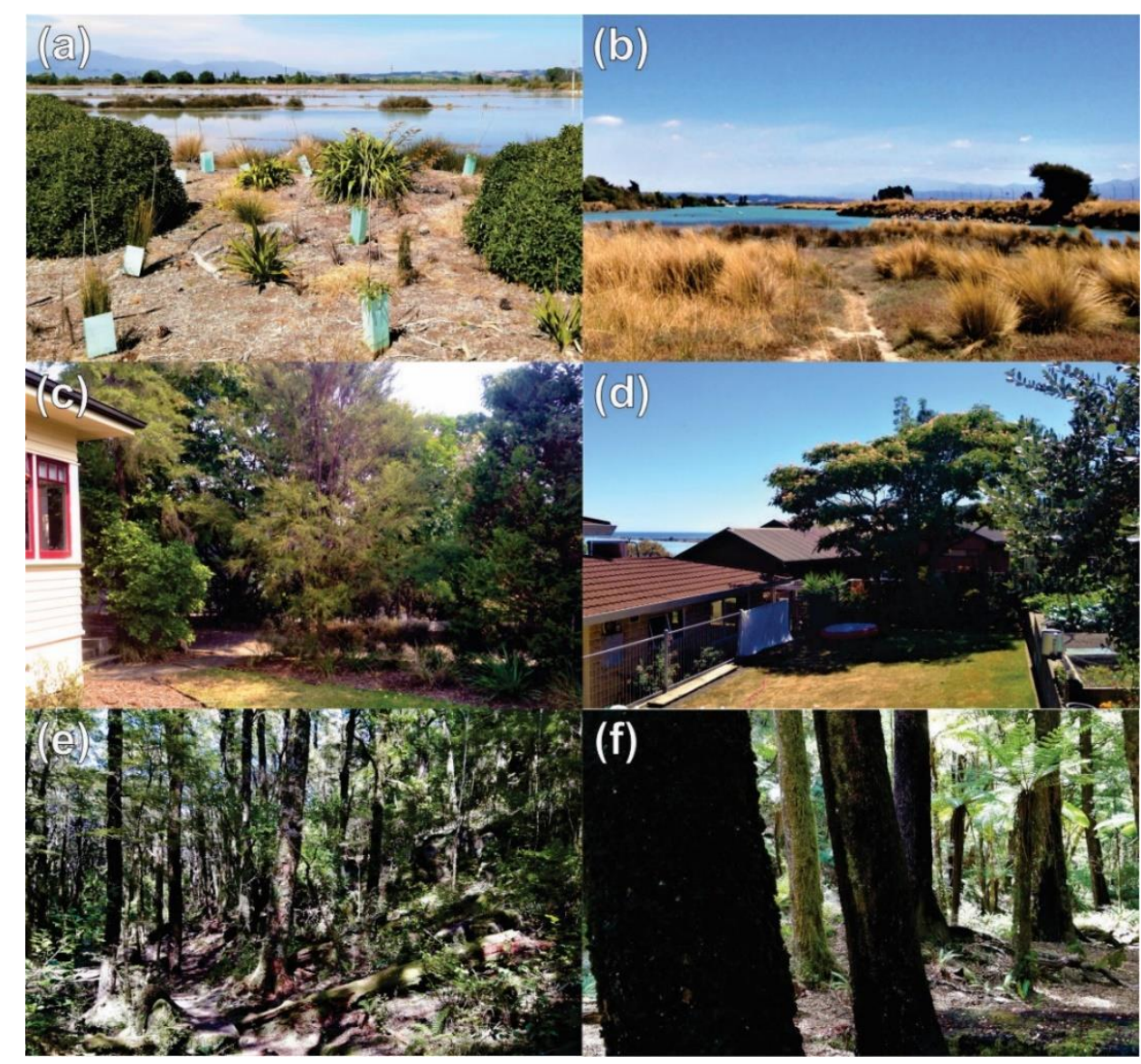

Fig. 2.2. Sites of differing habitat types that were searched for Polistes nests. Habitats were coastal ( $a$ and b), suburban (c and d) and forest (e and f). Note coastal site (a) contained plant protectors, which were utilized by both Polistes species. All sites searched were within the Nelson-Tasman region of New Zealand. Photo credit: Rose McGruddy. 


\section{Abundance and productivity}

The abundance and productivity of $P$. dominula in Nelson was compared to the longerestablished exotic congener $P$. chinensis. It should be noted that there is a third exotic congener, Polistes humilis Fabricius, in New Zealand, but this species is not present in Nelson. To compare nest productivity of $P$. dominula and $P$. chinensis, changes in nest size (number of cells) was recorded each week over both summers. The number of adult wasps on each nest were recorded over the summer of 2019-20 to compare changes in the abundance of both Polistes species over a season. Wasp densities were monitored every fortnight at five sites within each habitat type. These counts were conducted in the early hours of the day, typically between 6.30-9.00am when all wasps were likely to be present. An additional five suburban sites, one coastal and one forest were also monitored on a monthly basis to supplement fortnightly counts and provide a more robust estimate of wasp abundance. As not all sites were of the same size, the number of Polistes wasps was adjusted to give an estimate of abundance per $1,000 \mathrm{~m}^{2}$. For analysis, abundance was broken down into three main phases of the nesting cycle: founding phase, worker phase and reproductive phase. The founding phase, where the foundress(es) (or reproductively active individual), begins constructing the nest, laying eggs and feeding the subsequent larvae. The founding phase ends when the first adults emerge from the nest (Höcherl \& Tautz, 2015), therefore transitioning into the worker phase. During the worker phase, the nest grows in size at a greater rate and wasp densities increase as more workers emerge. The reproductive phase follows the worker phase, which is evident by the emergence of gynes (reproductive females) and males. There is also a slowing or complete stop to nest growth during this time. The reproductive phase is where wasp densities on each nest reach their peak.

\section{Nest survival rates}

Survival time in weeks was analysed from late spring, calendar week (CW) 47 in November $11^{\text {th }}, 2019$ until the end of the season in autumn around the $16^{\text {th }}$ of March 2020 (CW 13). To determine whether there was a preferable habitat for both $P$. dominula and $P$. chinensis, the abundance, growth and survival of nests were monitored each week. The substrate on which a foundress chose to nest was recorded 
as being either natural or manmade to determine whether this choice impacted a nest's chance of successfully surviving until the end of the season. Natural substrates were often the stems of small shrubs $(>1 \mathrm{~m})$, herbaceous plants, sedges and rocks. Manmade substrates included metal, treated timber, concrete or plastic. The number of foundresses on each nest was also recorded and verified in the fortnightly wasp count before the first workers emerged. Nests were classified as abandoned if, in addition to no wasps being present, the nests had either been emptied of eggs, larvae or pupae, or the nests were substantially damaged. Damaged nests that were truly abandoned were usually emptied of any remaining eggs or larvae by the next weekly count, most likely by ants. All nests were checked in subsequent weeks to ensure the nest had been abandoned and that no workers had successfully emerged.

\section{Translocation of $P$. dominula nests}

After completing the first summer of data collection, it became apparent that neither $P$. dominula nor $P$. chinensis nested in forest habitats, except in areas that had been disturbed by human modification. These forested sites were often surrounded by infestations of Polistes spp. wasps. Given the close proximity of Polistes spp. to these sites, it appears that dispersal ability was not the limiting factor preventing these wasps from establishing within these sites. Previous research on P. chinensis in New Zealand has demonstrated that this species is not commonly found in forest habitats (Clapperton et al., 1996; Ward \& Morgan, 2014). As a new invader to New Zealand, no similar research had been conducted on $P$. dominula. To determine whether $P$. dominula were not found in forests because they were unable to survive, a nest translocation experiment was conducted. This experiment was done in Nelson, from January $24^{\text {th }}$ until February $20^{\text {th }}, 2020$. This time period was selected as nests were in the worker phase when nest survival rates and wasp densities are higher than the founding phase, and therefore less likely to be abandoned due to bad weather, ant invasion or foundress death. Nests of $P$. dominula were attached to the inside of plastic containers ( $n=24$, Fig. 2.3). Eight nests were translocated into two forest habitats (four nests in each) and changes in nest growth, wasp densities and nest survival were monitored. One forest site was an industrial pine forest, the other regenerating native forest. The remaining nests were evenly divided and translocated into two suburban and two coastal habitats as controls. The number of cells per nest and the number of 
adult wasps were recorded before and after the experiment. Research has found temperature to have an important effect on Polistes nest growth (Höcherl \& Tautz, 2015) and foraging (Weiner et al., 2011), with wasps failing to forage for food at temperatures below $20^{\circ} \mathrm{C}$ (Kovac et al., 2019). To compare temperatures between habitats, HOBO Pendant ${ }^{\circledR}$ UA-001-08 temperature data loggers were placed within each site on the nest boxes. The proportion of hours that exceeded $20^{\circ} \mathrm{C}$ within each habitat type over the 28-day trial were then compared for analysis.

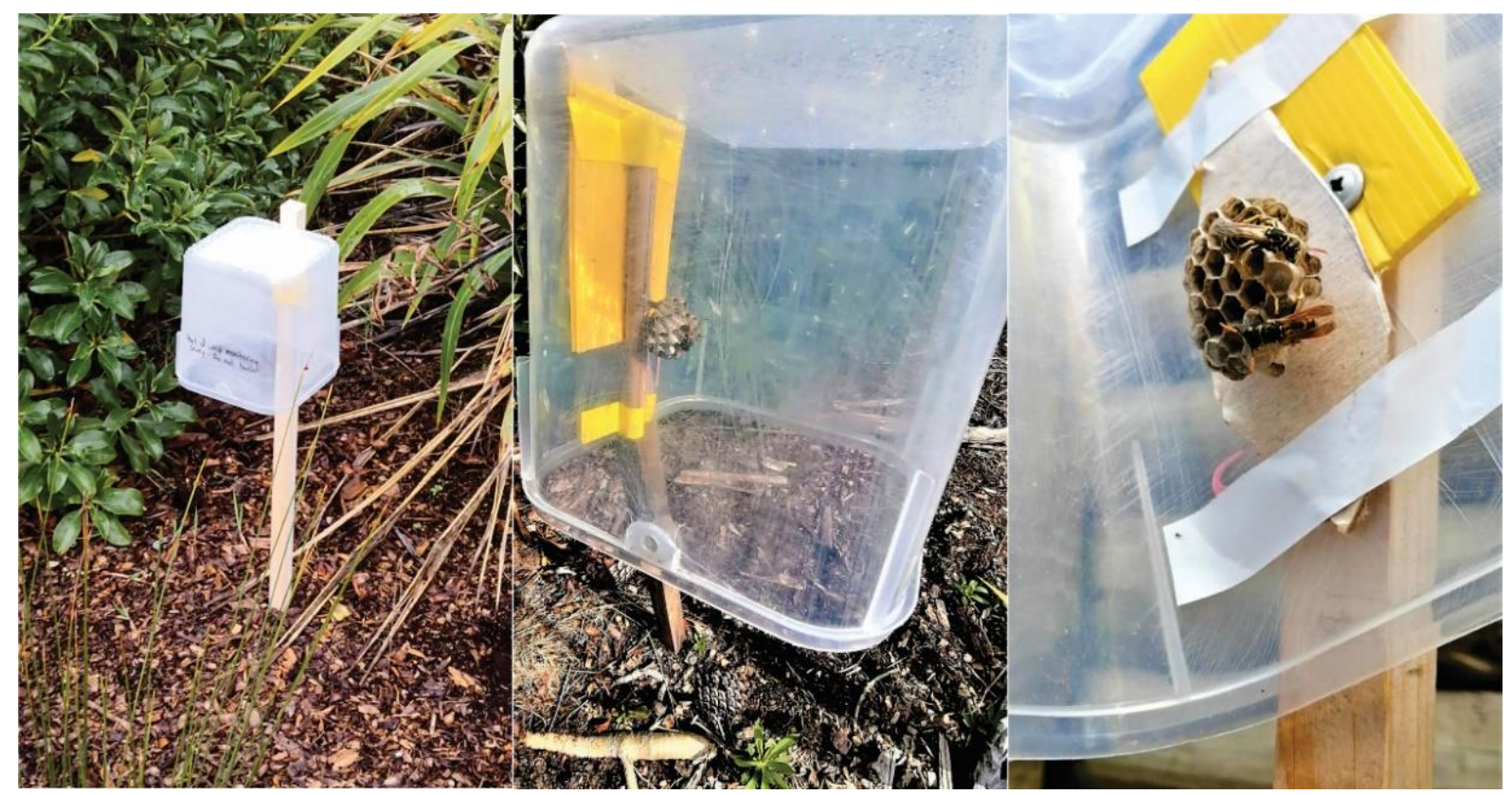

Fig. 2.3. Plastic nest boxes that were used for translocation experiment to discover whether $P$. dominula would be successful in forest habitats. The experiment was conducted for one month of the summer in 2020, in Nelson, New Zealand. Photo credit: Rose McGruddy and Matt Howse.

\section{Statistical analysis}

Statistical analyses were conducted in R 3.6.0 (R Development Core Team, 2020). To compare the abundance of wasps for both $P$. dominula and $P$. chinensis, a $2 \times 2$ factorial test was conducted with habitat type (coastal, suburban) and species ( $P$. dominula and $P$. chinensis) as factors at each of the three phases of the nesting season. The main effects of each treatment on the abundance of wasps per $1,000 \mathrm{~m}^{2}$ and interactions between factors were tested using a PerMANOVA, as the data was non-normal. The analyses were conducted using 'perm.anova' from the package 'RVAideMemoire' (Hervé \& Hervé, 2020).

Polistes nest survival was investigated using the packages 'survival' (Lin \& Zelterman, 2002) and 'survminer' (In \& Lee, 2019) to generate Kaplan-Meier plots to visualize 
survival curves. Differences between survival curves were then analysed using logrank tests. A logistic regression with data fitted to a binary distribution was conducted on nest survival for each Polistes spp. using the 'Ime4' package (Bates et al., 2014), with nest substrate and number of foundresses as factors and site as a random effect. As data failed to meet the assumption of normality, a PerMANOVA was conducted on changes in nest size and wasp densities of translocated nests using the 'vegan' package (Dixon, 2003). The factor in the model was habitat type, with initial nest size and initial wasp abundance included as covariates. Differences in the proportion of hours that were equal to, or over temperatures of $20^{\circ} \mathrm{C}$ within each habitat were tested using a Chi-squared test.

\section{Results}

\section{Abundance and productivity}

Nests of $P$. dominula and $P$. chinensis were monitored once a week to record changes in nest size (number of cells) during the summer seasons of 2018/19 and 2019/20. During the summer of 2018/19, 124 P. dominula and $67 P$. chinensis nests were found across 18 locations. In the following year, we monitored $94 P$. dominula and $195 P$. chinensis nests across 10 locations. All monitored nests were within coastal or suburban areas (Fig. 2.4), as no nests of either Polistes species were found within forest habitats. Nests were discovered in the final stages of the founding phase in late spring/early summer (calendar week (CW) 46-50). Over the nesting season, $P$. dominula nests typically had more cells than the nests of $P$. chinensis (Fig. 2.5). More cells in a nest increases the probability of a greater reproductive output (Pickett \& Wenzel, 2000). Polistes dominula workers began emerging around CW 48, with $80 \%$ of nests in 2018-19 and 84\% of nests in 2019-20 having workers by CW 2. By comparison, workers of $P$. chinensis emerged slightly later, with workers beginning to emerge in CW 49 and only $70 \%$ and $53 \%$ of nests having workers by CW 2 for the summers of 2018-19 and 2019-20, respectively. Nests at CW 2 were larger for $P$. dominula (mean: 58.9 cells, SE: 4.16 ) than for $P$. chinensis (mean: 46.7 cells, SE: 2.49). Once the workers had emerged, the number of cells added to the nest each week increased substantially for both species. 


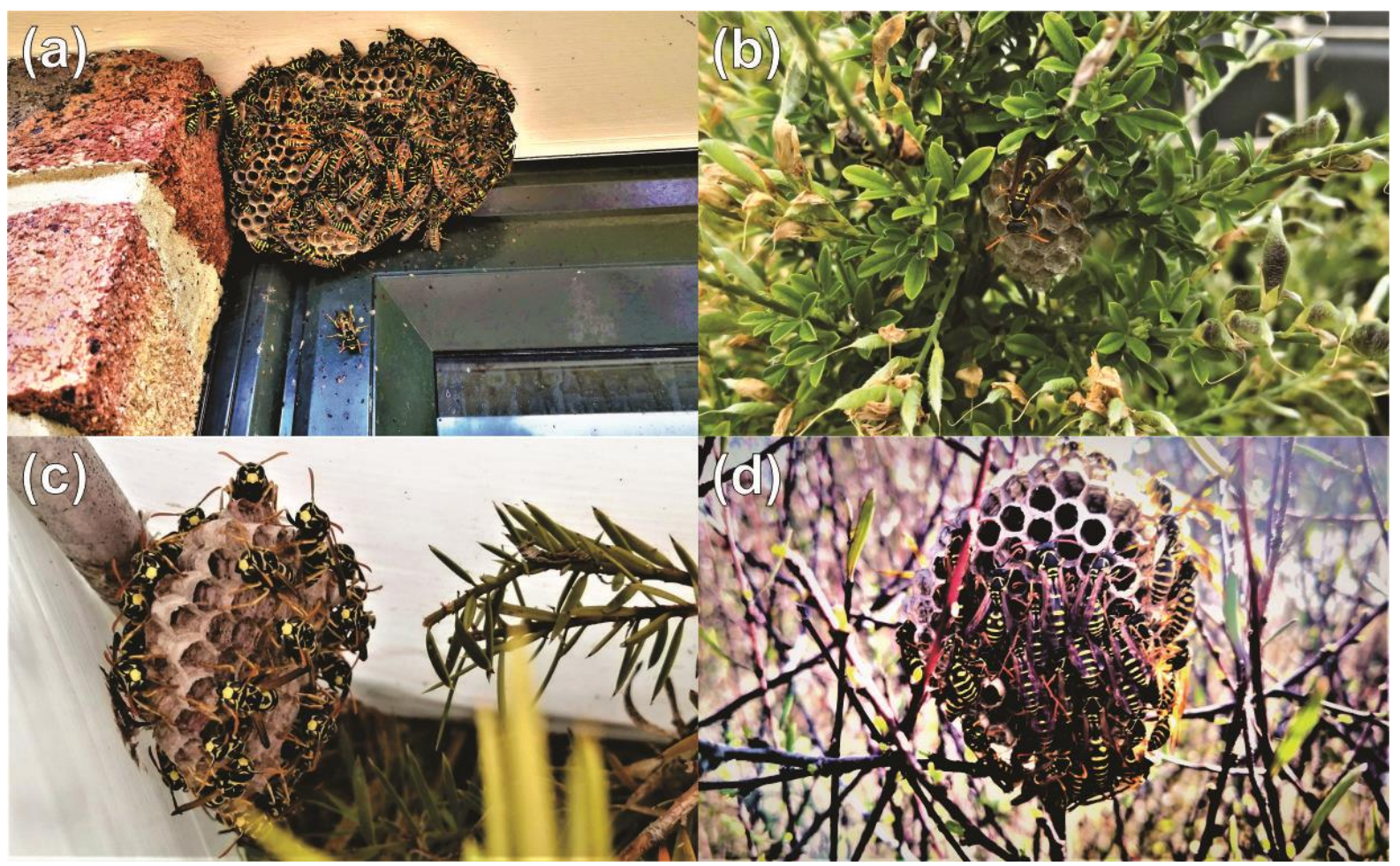

Fig. 2.4. Polistes nests monitored over the nesting season: (a) $P$. dominula nest on a house in a suburban site, (b) $P$. chinensis nest in the garden of a suburban site, (c) $P$. dominula nest inside a plant protector in a coastal site and (d) $P$. chinensis nest on a shrub in a coastal site. The wasps shown are approximately $2 \mathrm{~cm}$ long. Photo credit: Rose McGruddy and Matt Howse.

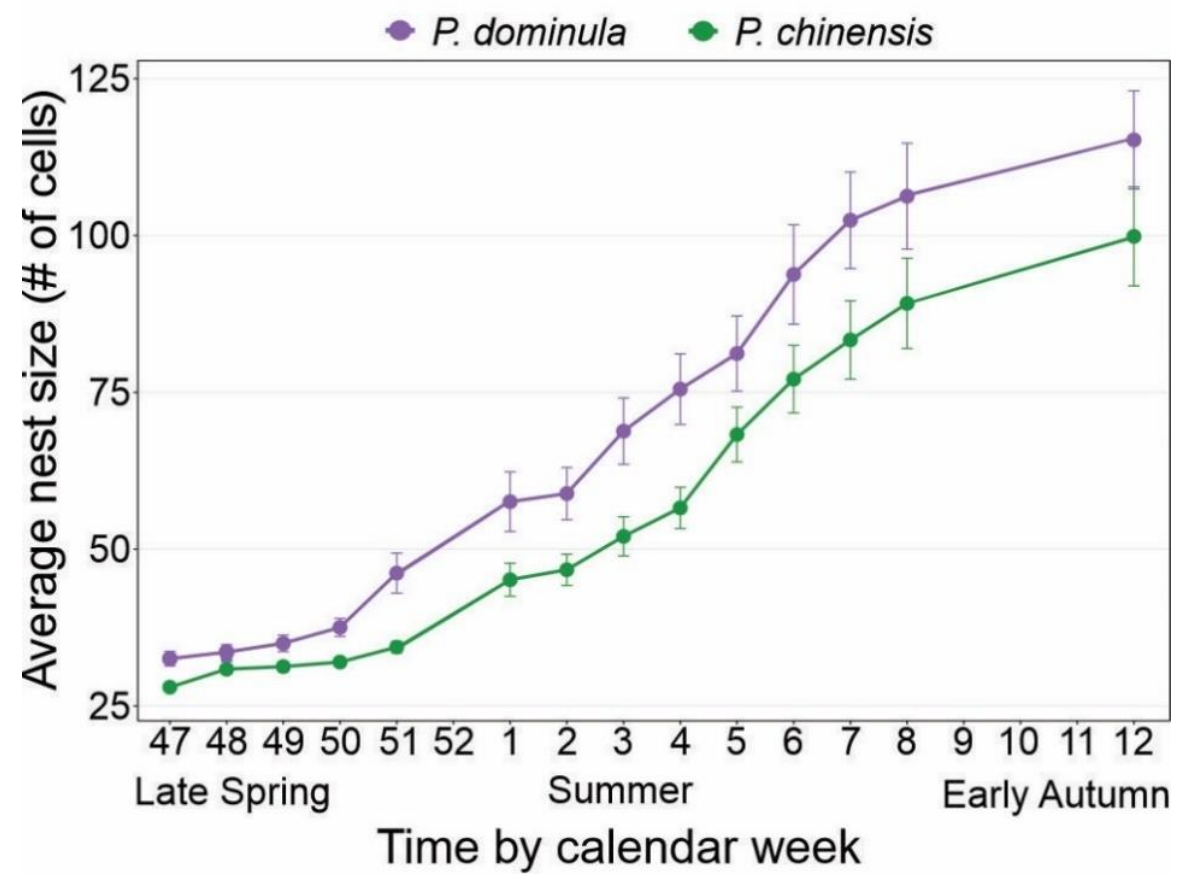

Fig. 2.5. The average nest size (number of cells) \pm 1 SE of $P$. dominula and $P$. chinensis over 18 weeks of the nesting season for two years (2018-19 and 2019-20) in Nelson, New Zealand. Gaps in the data are for weeks where no nests were monitored. A total of 246 P. dominula nests and 280 $P$. chinensis nests contributed to this analysis. 
During the founding phase, species had a significant main effect on wasp abundance (PerMANOVA: $F_{1,28}=4.87, P=0.033$ ) with $P$. dominula reaching higher densities (mean: 12.1 wasps per $1,000 \mathrm{~m}^{2}$, SE: 2.58 ) than $P$. chinensis (mean: 5.08 wasps per $1,000 \mathrm{~m}^{2}$, SE: 2.23, Fig. 5). This difference is likely explained, in part, by co-founding which is frequently exhibited by $P$. dominula, with one-third of nests in this study having more than one foundress. Co-founding involves multiple foundresses working together to build the nest, feed larvae and defend the nest. Having multiple foundresses increases the number of wasps per nest at the founding phase of the nesting season. Co-founding is rarely exhibited by $P$. chinensis, so only a single foundress is expanding the nest and feeding larvae at this time (Clapperton \& Dymock, 1997; Miyano, 1980). Habitat had no main effect on wasp abundance at the founding phase of the nesting season (PerMANOVA: $\mathrm{F}_{1,28}=2.73, P=0.115$ ). During the worker phase, species was again found to have a main effect on wasp abundance (PerMANOVA: $F_{1,28}=11.21, P=0.002$, Fig. 2.6). There was an average abundance of 21.3 (SE: 4.57) P. dominula wasps per $1,000 \mathrm{~m}^{2}$ across habitats compared to the 5.1 (SE: 2.11) $P$. chinensis wasps per $1,000 \mathrm{~m}^{2}$. This difference in abundance is likely due to the higher failure rates of $P$. chinensis nests and the comparatively earlier emergence time and population growth of $P$. dominula. By the reproductive phase (CW 8), species and habitat had strong interactive effects on wasp abundance (PerMANOVA: $F_{1,28}=4.47$, $P=0.037$, Fig. 2.6).

Suburban habitats had the highest abundance of paper wasps, which were predominantly comprised of $P$. dominula (Fig. 2.6). In suburban habitats, the average abundance of $P$. dominula and $P$. chinensis at the peak of the nesting season was 87.4 (SE: 21.0) and 9.1 (SE: 7.30) wasps per $1,000 \mathrm{~m}^{2}$, respectively. In coastal habitats, the abundance of $P$. dominula was 26.5 (SE: 16.10) wasps per $1,000 \mathrm{~m}^{2}$ and for $P$. chinensis, 15.4 (SE: 5.50 ) wasps per $1,000 \mathrm{~m}^{2}$. In summary, these results indicate that $P$. dominula thrives in suburban habitats and was typically over 9-fold more abundant in these areas than $P$. chinensis at the peak of the nesting season. The more recently arrived $P$. dominula was also more abundant than $P$. chinensis in coastal areas. 


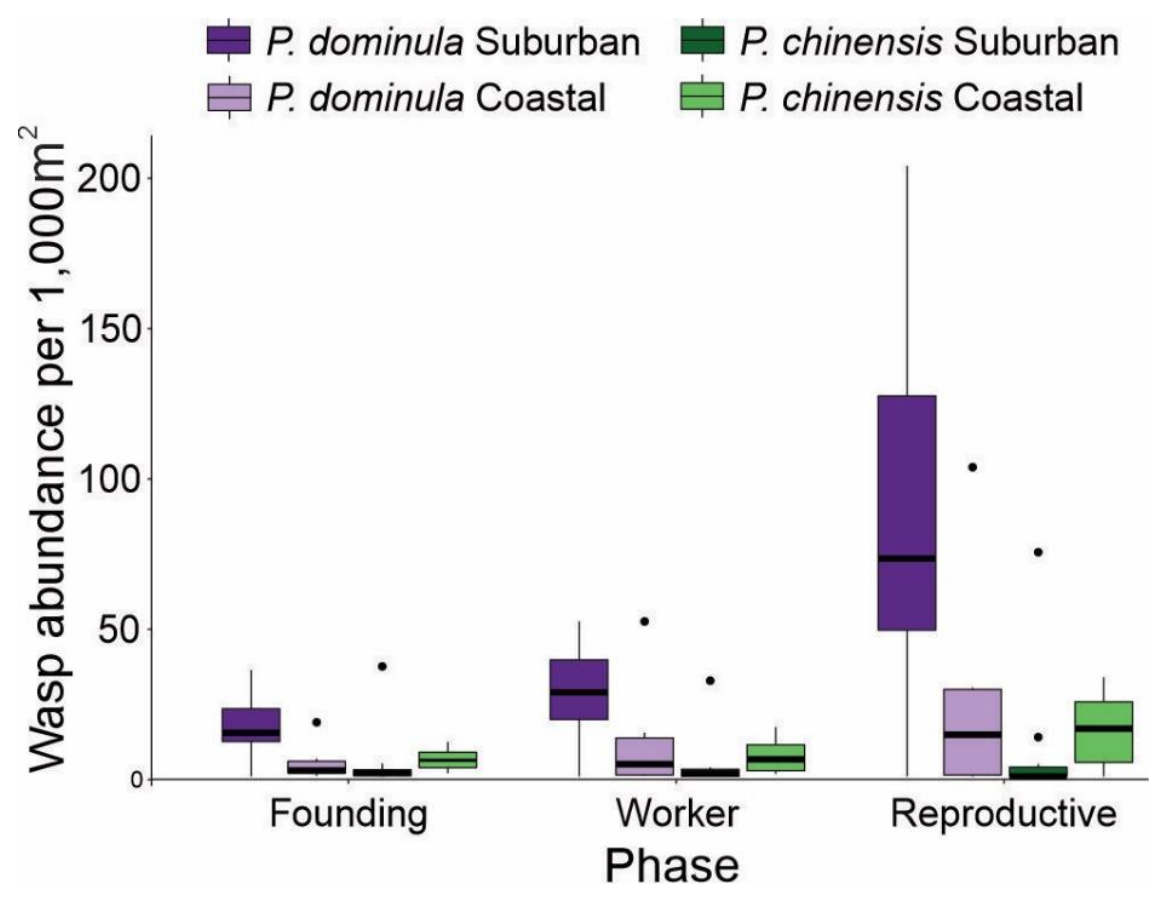

Fig. 2.6. Boxplots showing the abundance of $P$. dominula and $P$. chinensis per $1,000 \mathrm{~m}^{2}$ based on habitat type spanning 18 weeks of the nesting season for the summer of 2019-20 in Nelson, New Zealand. Habitat types were suburban $(n=10)$ and coastal $(n=6)$. Nests were surveyed at three points in time: the founding phase in November (CW 48), after worker emergence in January ( $\mathrm{CW} 2$ ) and during the reproductive phase in February (CW 8).

\section{Nest survival}

Nests of $P$. dominula had a higher survival rate over a season compared to $P$. chinensis (log-rank test, $X^{2}=20.8 ; P<0.001$ ), with $46 \%$ of $P$. dominula nests surviving until the end of the season, compared with only $21 \%$ of $P$. chinensis nests that survived. Nest survival for $P$. dominula was greater for nests built in suburban habitats, with $72 \%$ of $P$. dominula nests surviving until the end of the season, whereas only $31 \%$ of coastal nests survived (log-rank test, $X^{2}=17.5 ; P<0.001$, Fig. 2.7a). The odds of nest success were 5.4 times higher for $P$. dominula nests built on manmade substrates compared to nests built on natural substrates ( $P=0.016$, Fig. 2.8). It should be of note that of the nests that survived within coastal sites, $90 \%$ were built within manmade plant protectors (Fig. 2.2a). Nests were either built on the plant within the protector, the supporting bamboo stick keeping the protector in place, or on the plastic of the protector itself. These protectors probably provided wind and rain protection, plus the benefit of a warmer temperature. There was no significant difference in $P$. chinensis 
nest survival between habitats (log-rank test, $X^{2}=0 ; P=0.899$, Fig. 2.8). Of the 220 $P$. chinensis nests that were monitored for survival, $76 \%$ were built in coastal sites, suggesting there was a preference for these areas, despite the fact they conferred no survival advantage. Nest substrate for $P$. chinensis also did not significantly affect nest survival ( $P=0.821$, Fig. 2.8). Further information on the nest substrates utilized by each species can be viewed in Appendix A (Tables A1 \& A1).
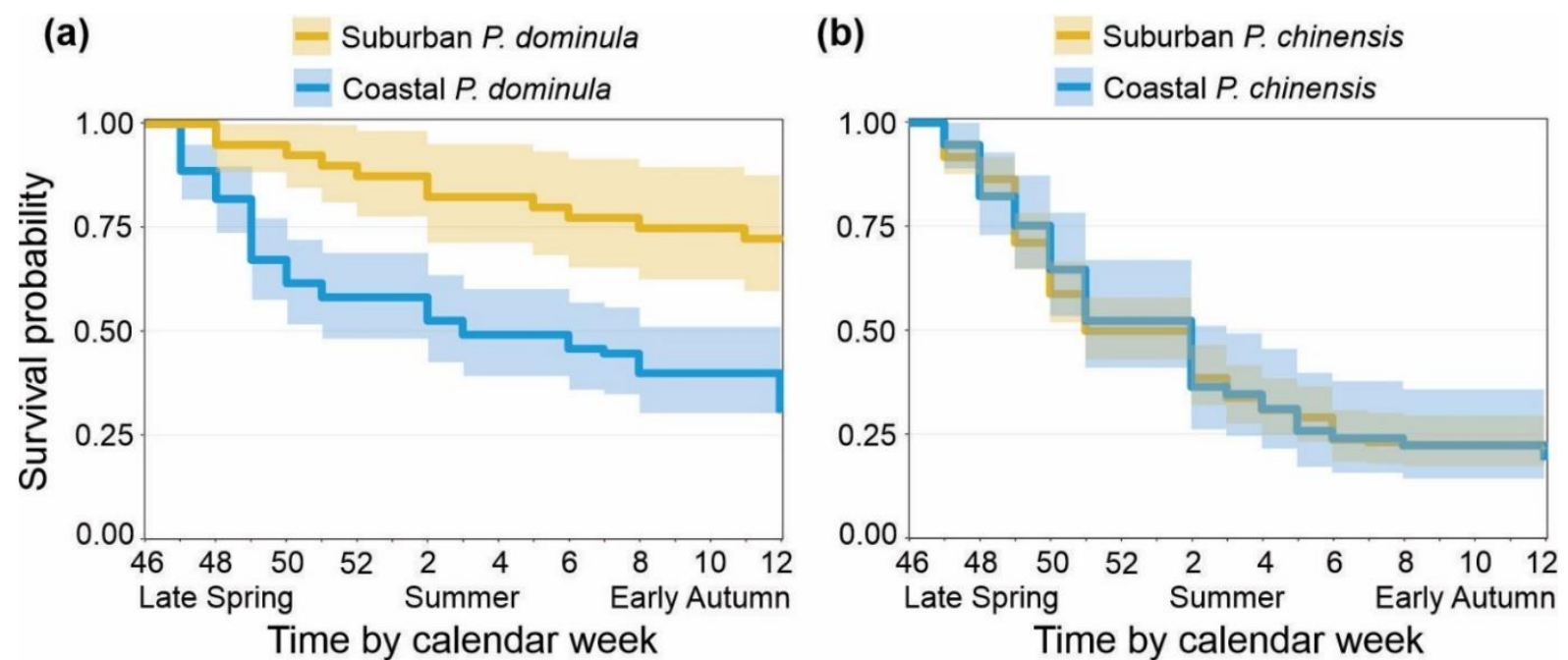

Fig. 2.7. Kaplan-Meier survival estimates $( \pm 95 \% \mathrm{Cl})$ on the nest survival of (a) $P$. dominula $(\mathrm{n}=$ $129)$ and $(b) P$. chinensis $(\mathrm{n}=220)$ based on habitat type (suburban and coastal) over 18 weeks of the nesting season in Nelson, New Zealand. Survival curves are the results of the summer 201920. A log-rank test was used to compare the survival of nests for $P$. dominula and $P$. chinensis in each type of habitat. 
(a)

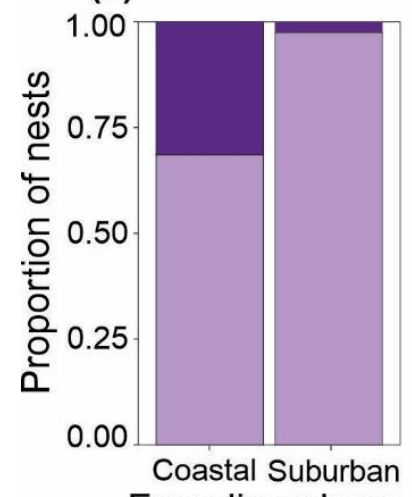

Founding phase
Manmade

(b)

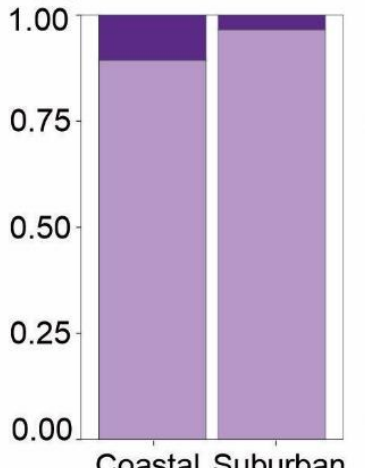

Reproductive phase (c)

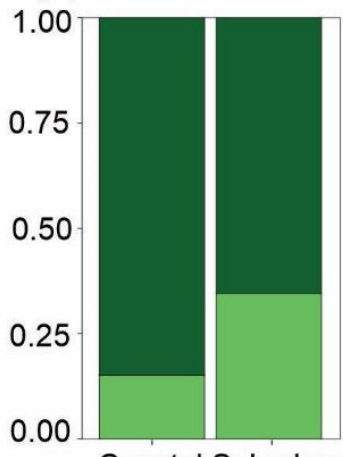

Coastal Suburban Founding phase (d)

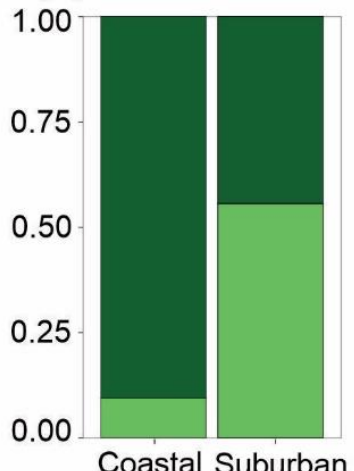

Polistes chinensis

Fig. 2.8. The proportion of active nests built on natural/manmade substrates for (a) $P$. dominula during the founding phase at the start of the season $(n=129)$ and $(b)$ the proportion of $P$. dominula nests built on natural/manmade substrates that survived until the reproductive phase near the end of the season $(n=57)$. The proportion of active nests of $P$. chinensis based on substrate are also presented in (c) the founding phase $(n=220)$ and $(d)$ reproductive phase $(n=41)$. Nests are split into two habitat types (coastal and suburban). Data presented is for the summer of 2019-20 in Nelson, New Zealand.

In the summer of $2019 / 20,30 \%$ of $P$. dominula nests had two or more foundresses. The number of foundresses present was found to significantly affect nest survival ( $P$ $=0.015$ ), with the odds of nest success increasing by $68 \%$ for each foundress present on the nest. Of the nests with two or more foundresses, $72 \%$ survived, whereas singlefoundress nests had a survival rate of only $27 \%$ (Fig. 2.9a). The maximum number of $P$. dominula foundresses observed on a nest was ten. Only $4 \%$ of $P$. chinensis nests had more than one foundress, and the maximum number of foundresses observed on a nest was two. Nests of $P$. chinensis did not appear to have an increased chance of survival compared to nests with a single foundress, with survival rates of $22 \%$ and $20 \%$ respectively (Fig. 2.9b). The rarity of co-founding observed for $P$. chinensis in this experiment was in accordance with findings from previous research (Clapperton \& Dymock, 1997; Miyano, 1980). 


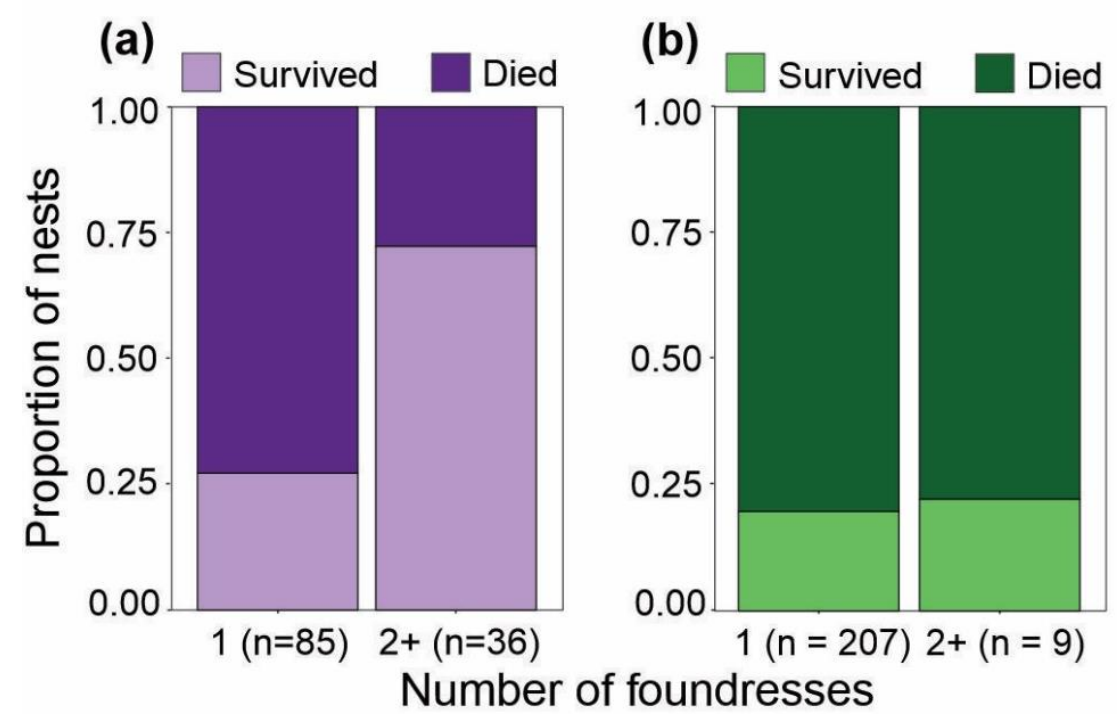

Fig. 2.9. The proportion of (a) $P$. dominula and (b) $P$. chinensis nests that survived based on foundress number over 18 weeks of the nesting season of 2019-20 in Nelson, New Zealand. For P. dominula, as many as 10 gynes co-founded the nest, whereas for $P$. chinensis the maximum number of foundresses observed was two.

\section{Translocated nests}

Habitat had a significant effect on $P$. dominula nest growth and wasp abundance in the translocation experiment (PerMANOVA: $F_{2,19}=4.01, P=0.028$, Fig. 2.10). Nests placed within forest habitats only increased by an average of 0.1 cells (SE: 0.12 ) in a month, whereas nests in coastal and suburban sites increased by an average of 6.62 cells (SE: 2.39) and 10.6 cells (SE: 4.50 ), respectively (Table A3). Wasp abundance in forest habitats decreased (mean: -0.1 wasps, SE: 2.30 ) with only $50 \%$ of nests translocated into this habitat surviving the 28-day trial. In suburban habitats, wasp abundance increased by an average of 4.4 wasps (SE: 2.70 ), with $75 \%$ of nests surviving. In coastal habitats, wasp abundance increased by 3.6 wasps (SE: 1.71) and $100 \%$ of nests survived. The proportion of hours where the temperature exceeded $20^{\circ} \mathrm{C}$ for the 28 days of the experiment differed significantly between habitat types $\left(X^{2}=\right.$ $80.3, P<0.001$, Fig. S1). Forest habitats had the lowest number of hours meeting or exceeding $20^{\circ} \mathrm{C}$, with only $36 \%$ of the hours monitored reaching these temperatures. This differed significantly to the proportion of hours reaching $\geq 20^{\circ} \mathrm{C}$ in suburban (48\%) and coastal $(61 \%)$ habitats. Forest sites only reached a maximum of $30.1^{\circ} \mathrm{C}$, whereas suburban sites reached temperatures as high as $41.3^{\circ} \mathrm{C}$ and coastal sites reached $43.1^{\circ} \mathrm{C}$ (Table A4). 
(a)

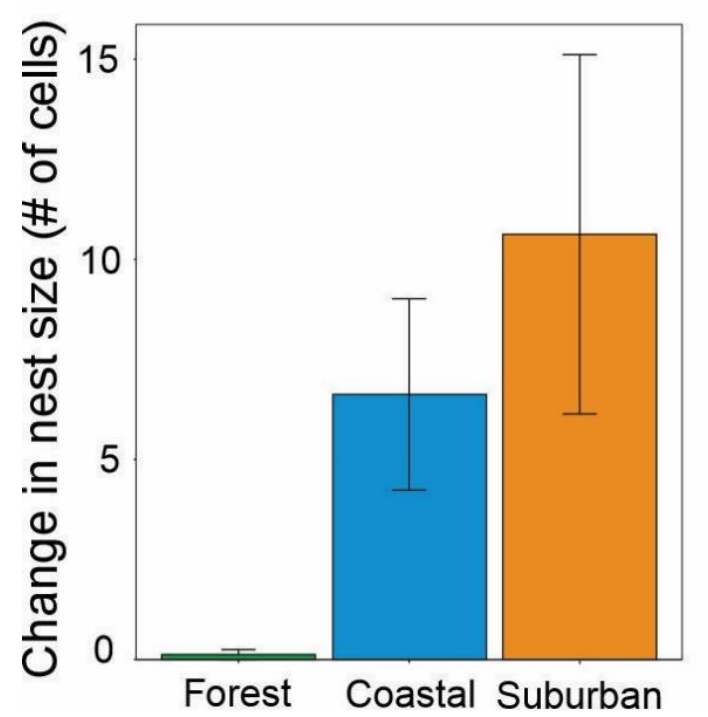

(b)

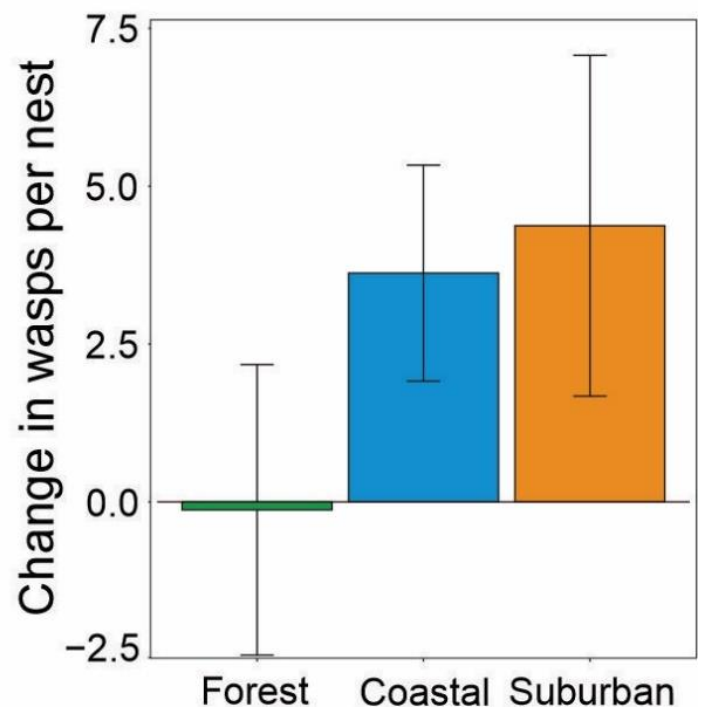

Fig. 2.10. Average changes in (a) nest size (\# of cells) \pm 1 SE and (b) number of $P$. dominula adult wasps per nest \pm 1 SE. Nests were translocated into three habitat types: forest, coastal and suburban ( $n=8$ nests per habitat type). Translocated nests were placed within each site for one month and changes to the number of cells and wasps per nest were compared across habitats.

\section{Discussion}

Our research on the abundance, nest growth and survival of $P$. dominula and $P$. chinensis found that $P$. dominula exhibited a strong habitat preference. Although habitat did not have a main effect on wasp abundance during the founding or worker phase, the interaction between habitat and species by the reproductive phase found $P$. dominula to be the most abundant species, reaching the greatest densities in suburban habitats. Across all phases of the nesting season, $P$. dominula was found in greater abundance relative to $P$. chinensis. Co-founding by $P$. dominula during the founding phase increased the number of wasps per nest. This advantage early in the season likely contributed to the earlier emergence of workers and higher abundance of $P$. dominula at the start of the worker phase. The habitat type in which $P$. chinensis were most abundant were coastal areas, although results of this research found the abundance of wasps for this species did not differ between habitat types. An unusually high abundance of $P$. chinensis nests (46 nests within an area of $1,300 \mathrm{~m}^{2}$ ) at a particular suburban site could provide a possible explanation for our insignificant results. This site contained a large number of small shrubs and grasses, which $P$. chinensis appears to preferentially nest upon. Previous research conducted in New 
Zealand has found $P$. chinensis to be most abundant in shrubland and flax salt meadow sites (Clapperton et al., 1996), which is what was observed within the majority of sites monitored in this study.

Nests of $P$. dominula were larger than $P$. chinensis over the nesting season. Workers of $P$. dominula emerged earlier than $P$. chinensis, which could have given $P$. dominula a competitive advantage, as the number of wasps per nest can be a significant predictor of nest growth (Grinsted \& Field, 2018). Studies comparing the productivity of $P$. dominula and another congener, $P$. fuscatus, also found $P$. dominula workers emerged relatively earlier (Gamboa et al., 2005; Pilowsky \& Starks, 2018).

The higher nest survival rates of $P$. dominula compared to $P$. chinensis were also in accordance with previous research that found $P$. dominula to be a successful invader and have advantages over congeners such as $P$. fuscatus and $P$. marginalis (Armstrong \& Stamp, 2003; Gamboa et al., 2004; Pilowsky \& Starks, 2018). Our results found survival of $P$. dominula nests to be highest in suburban habitats. It has been suggested that urban areas can provide warmer habitats for invasive wasps that originate from warmer climates (Sorvari, 2018). Polistes chinensis had a similar survival rate across both habitat types, suggesting there was no survival advantage for this species to nest in either coastal or suburban sites. Nest survival rates for $P$. chinensis were similar to those observed previously in New Zealand, where overall colony survival was 22-25\% (Clapperton \& Dymock, 1997). Whilst no Polistes nests were found under the canopy of forest habitats, nests could be found in open areas created by human disturbances (walking tracks, campsites etc.), predominantly on anthropogenic structures. Research has found $P$. dominula does nest within forest habitats, but in that particular study the forest sites were in close proximity to the forest edge $(<50 \mathrm{~m})$ (Gamboa et al., 2005). A citizen science project conducted in New Zealand found some paper wasps in forest habitats, however, they were individual wasps, not nests, and it was unclear how far into the forest habitat those individuals were found (Clapperton et al., 1996). A significant, negative correlation has also been observed between canopy cover and both Polistes and Vespula spp. wasp densities elsewhere in New Zealand (Schmack et al., 2020).

Nest substrate was found to significantly affect nest survival for $P$. dominula, as the majority of nests that survived the nesting season were built on manmade substrates. This behavior of nesting on manmade substrates has been observed for numerous 
social wasp species in urban areas and may be an advantageous strategy, as it can provide shelter from harsh weather conditions and protect against many natural predators (Detoni et al., 2018). However, it has also been found that in urban environments, human activity is the main cause of nest failure (Perez-Bote et al., 2020; Reed \& Vinson, 1979). Polistes chinensis evidently does not utilize manmade structures to the same extent as $P$. dominula, as only half of all $P$. chinensis nests that survived until the reproductive phase in suburban areas were built on manmade substrates. Similar results on the use of manmade structures as nesting sites were observed in an earlier study of $P$. chinensis in New Zealand, prior to the establishment of $P$. dominula (Clapperton \& Lo, 2000).

Having more than one foundress per nest provided a survival advantage for $P$. dominula nests, which has been observed in other areas of this species' range (Höcherl \& Tautz, 2015; Tibbetts \& Reeve, 2003). Co-founding acts as a safeguard if a foundress dies before the worker phase, as the other foundress(es) can keep the colony alive. It also has the potential to increase the amount of food that can be gathered to feed larvae, which could explain why workers hatched earlier in the season relative to $P$. chinensis. Co-founding is seldom used as a strategy by $P$. chinensis, as so few nests had more than one foundress. Multiple founding by this species is also uncommon within its native range of East Asia (Miyano, 1980). Co-operative nesting in Polistes wasps is likely driven by climate, with multiple founding observed in paper wasps, such as $P$. dominula, from warmer and wetter climates (Sheehan et al., 2015). Nests of $P$. dominula failed to thrive in forest habitats in our translocation experiment. The nests did not grow in size and half of the nests were abandoned by their foundresses and workers. Polistes nests have been found to grow larger with faster larval development and more offspring in sun-warmed sites than in cooler sites (Inagawa et al., 2001). It has also been suggested that $P$. dominula does not forage for food at temperatures below $20^{\circ} \mathrm{C}$ (Kovac et al., 2019; Weiner et al., 2011). In our experiment, forest sites had the lowest proportion of hours that reached or exceeded $20^{\circ} \mathrm{C}$. These cooler temperatures may have prevented wasps from reaching the body temperature necessary for flight as frequently as was required for nest survival. Reduced foraging time could lead to starvation of both the adults and larvae, driving the adults to abandon the nest. 
Understanding the nesting ecology and habitat preference of invasive wasps can help inform managers of the potential risks that each species can pose within its newly invaded range. Polistes dominula has proven itself to be a suburban species, not only in New Zealand, but also in other areas of its native and invaded range (Gamboa et al., 2005; Roets et al., 2019). By reaching such high abundances in suburban areas, this species is likely to have a greater impact on human health than $P$. chinensis, as there is the potential for a greater frequency of wasp stings. As predators, these species will also impact New Zealand's ecosystems. The diets of the two species differ to some extent, with $P$. chinensis predominantly predating upon Lepidopteran larvae (Ward \& Ramón-Laca, 2013), whereas $P$. dominula has a broader and more generalist diet (Howse et al., 2021). Whilst $P$. dominula was less abundant in coastal habitats, this species can thrive in these areas. As $P$. chinensis is also prominent in these habitats, coastal communities are likely experiencing extra pressure from the presence of these two predators. Research on $P$. chinensis has found this species capable of consuming large quantities of prey (Clapperton, 1999). The impact of $P$. dominula on communities in New Zealand has also proven to be significant, with declines in Lepidopteran species since this predator's arrival (McGruddy et al., 2020). This is of concern for New Zealand's local invertebrate communities, as an increase in the abundance of invasive species tend to cause a decline in native populations and communities (Bradley et al., 2019). The discovery in the current study that neither Polistes species nest within forest habitats, suggest these wasps are unlikely to have a significant impact on invertebrate species in these areas. The findings of this research have management implications, as conservation and biodiversity managers can be guided to where protection is most needed, specifically urban and coastal habitats, but not forest environments. We have identified areas most at risk of these invasive wasps and when these pests will reach their highest densities. Moving forward, considerable work is needed to slow the spread of $P$. dominula to other parts of New Zealand and improve current control strategies for both Polistes species. 


\title{
Chapter 3: Invasive paper wasps have strong cascading effects on the host plant of monarch butterflies
}

\begin{abstract}
The direct and indirect impacts that invasive predators have on communities within their invaded range are poorly understood, particularly in the early stages of invasion. Through top-down control of their prey, predators have the capacity to trigger cascading effects on lower trophic levels. We found the recent arrival of the invasive paper wasp Polistes dominula Christ has been associated with substantial declines in local butterfly abundance in New Zealand. One of the butterfly species we observed to be affected is the monarch, Danaus plexippus Linnaeus with densities reduced by $66 \%$ at the study site. Field experiments were conducted to examine the strength of the predation pressure exerted by $P$. dominula on monarch caterpillars and the cascading effects on milkweed (Gomphocarpus physocarpus E. Mey.) fitness. A survival study of monarch caterpillars was conducted across three habitat types (coastal, forest and suburban). Caterpillar survival in suburban areas was lowest, with only $45 \%$ of caterpillars remaining after just six hours of exposure to wasp foraging. Predation by $P$. dominula explained $85 \%$ of caterpillar deaths within the trial period. The cascading effects of $P$. dominula presence were quantified through changes in the height, foliage and reproductive output of milkweed plants. Monarch caterpillar predation by $P$. dominula was found to have a positive effect on milkweed fitness. This study demonstrates a strong trophic cascade initiated by an invasive predator. These findings highlight the impacts an invasive species can have on local communities beyond their direct predatory effects.
\end{abstract}

\section{Introduction}

Predation has been widely demonstrated as an important biotic process, influencing the density and distribution of prey (Moon \& Silva, 2013; Terborgh et al., 2001; Worm \& Myers, 2003). The effects of this top-down control on prey population dynamics can 
extend indirectly to lower trophic levels (Borer et al., 2006; Halaj \& Wise, 2001; Liere et al., 2015). Predators therefore have the capacity to structure communities and alter species diversity (Beschta \& Ripple, 2009; Britten et al., 2014; Shears \& Babcock, 2002). However, invasive predators can have detrimental effects on communities, as prey species often do not share an evolutionary or ecological history with the intruder (Gurevitch \& Padilla, 2004; Salo et al., 2007). This novelty leaves prey vulnerable to exploitation by the invasive predator, which can have flow-on effects for other trophic levels (O'Dowd et al., 2003)

Hymenopteran insects are particularly successful invaders, with the ability to have substantial impacts on native biodiversity (Lester \& Beggs, 2019). These invasive predators and their capacity to decimate native invertebrate communities directly has been well documented (Beggs \& Rees, 1999; Potter-Craven et al., 2018; Toft \& Rees, 1998). Yet the indirect effects these predators can have on lower trophic levels within their invaded range has received less attention. Due to the invasion success and strong predatory effects of these social insects, they are likely to be important instigators of trophic cascades (Holway et al., 2002; Rosumek et al., 2009).

We examined both the direct and indirect effects of the invasive European paper wasp Polistes dominula Christ. This predatory wasp has successfully invaded several continents (Benade et al., 2014; Cervo et al., 2000; Liebert et al., 2006), including a recent invasion of New Zealand in the last decade. The presence of this invader was first realised in New Zealand in the summer of 2015, although it has been estimated that $P$. dominula could have arrived as early as 2011 (MPI, 2016). This wasp is a generalist predator, which preys upon a variety of Lepidopteran species (Cervo et al., 2000), including the monarch butterfly, Danaus plexippus Linnaeus (Rayor, 2004).

In this study, larvae of the monarch butterfly and their milkweed host plant (Gomphocarpus physocarpus E. Mey.) were used to test the direct and indirect effects of $P$. dominula. Native to North America, the monarch butterfly is an assisted immigrant in New Zealand, first recorded in the early 1840s (Zalucki \& Clarke, 2004). The introduction of milkweed plants, which host monarch caterpillars, was necessary for this butterfly to successfully establish and persist in New Zealand (Wise, 1980). Anecdotally, a decline has been observed in monarchs and other Lepidopteran populations in the Nelson region of New Zealand over the last decade, with residents attributing the cause to the newly invasive paper wasp $P$. dominula. There are other 
possible explanations for these declines, however, as $P$. dominula is not the first paper wasp to invade New Zealand. A close relative, the Asian paper wasp, Polistes chinensis Pérez, invaded in the 1970s and since then has become well established in many parts of the country (Clapperton et al., 1996). Monarch caterpillars, among other Lepidopteran larvae, are prey species of $P$. chinensis in New Zealand (Ward \& Ramón-Laca, 2013). Predation pressure exerted by $P$. dominula alone, or in addition to predation by the already established $P$. chinensis, could be instigating these butterfly declines. Discovering the driver behind these declines in Lepidopteran populations is important as there are implications for the wider invertebrate community and conservation efforts (Beggs et al., 2011; Beggs \& Rees, 1999; Brockerhoff et al., 2010).

We present the results of an annual butterfly survey, which exhibited changes in Lepidopteran populations following the arrival of $P$. dominula. We also examined the direct effects of this predatory, invasive wasp on monarch caterpillars and the indirect effects of this predator-prey interaction on the fitness of the milkweed host plant. In a field experiment, the survival rates of monarch caterpillars within suburban, coastal and forest habitats were recorded. We hypothesized that $P$. dominula would be the primary cause of caterpillar mortality. We also predicted that through the direct predation of monarch caterpillars, paper wasps would indirectly alter plant biomass and fitness (Fig. 3.1). Released from herbivory, introduced milkweed, with a high reproductive rate, wind dispersal and few other herbivores, has the potential to become so abundant that people could perceive it as a pest.

\section{Methods}

Annual survey of butterfly abundance

The estimates of annual butterfly abundance were undertaken using a citizen science project. A transect walk was conducted in the residential area of Nelson $\left(41.2985^{\circ} \mathrm{S}\right.$, $\left.173.2441^{\circ} \mathrm{E}\right)$, from 2009 to 2020 recording adult abundance of three common Lepidopteran species (D. plexippus, Pieris rapae Linnaeus, 1758 and Zizina labradus Godart). The transect line was $4.7 \mathrm{~km}$ long and the walk was conducted roughly once a week over the summer from December until March. Walks were undertaken between the daylight hours of $10 \mathrm{am}$ and $4 \mathrm{pm}$ on days with calm weather. The walk 
encompassed a mixture of suburban streets and riverside reserves. All butterflies that were identifiable as far as the eye could see from the transect line were recorded.

Fig. 3.1. Trophic interactions between the predator $P$. dominula, monarch caterpillar herbivore and primary producer $G$. physocarpus. The wasp has negative, direct effects on caterpillars through predation. Caterpillars have negative, direct effects on the host plant through herbivory. The predicted beneficial, indirect effects of wasp predation for host plant fitness is represented by the dashed line. Photo credit: Philip Lester and Rose McGruddy.

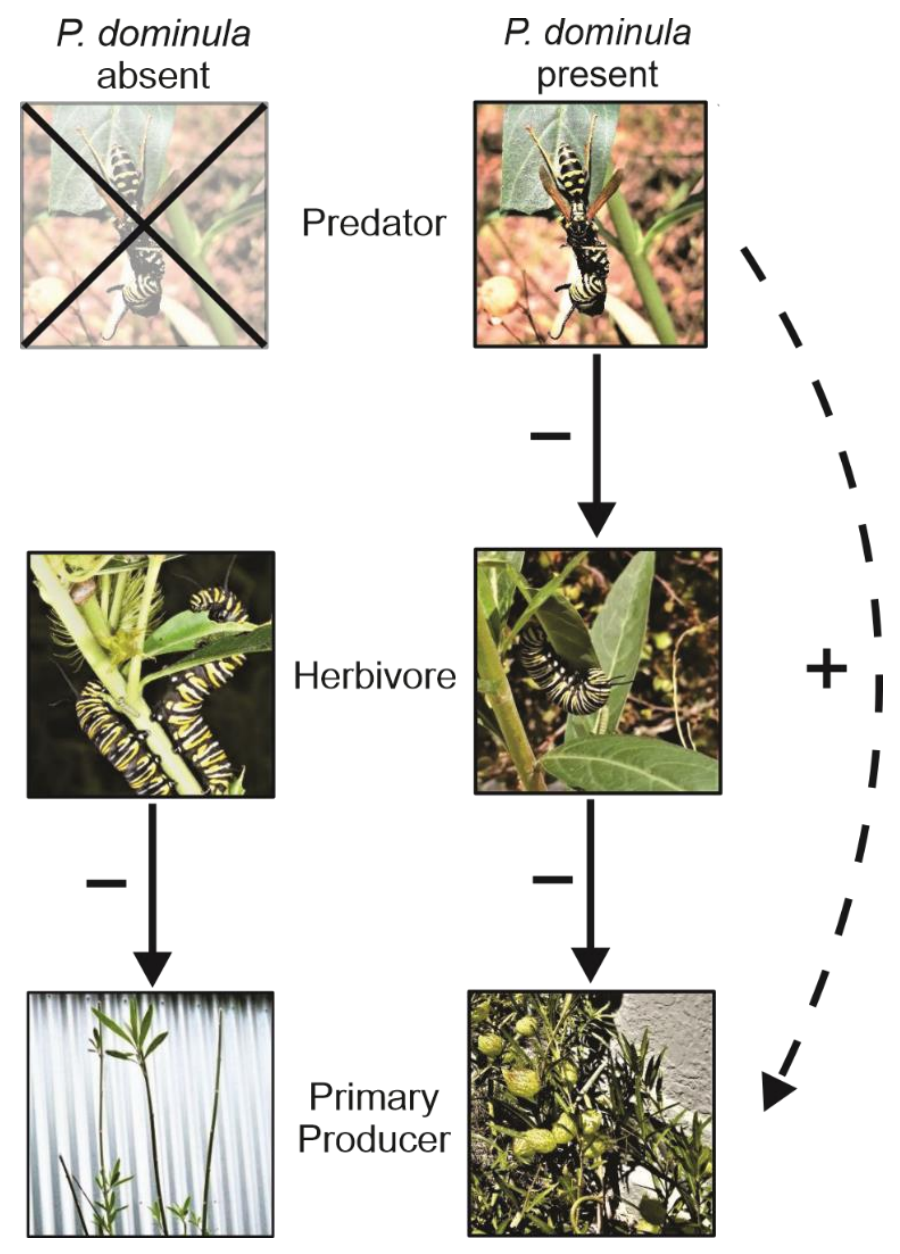

\section{Experiment 1 - Predation of caterpillars by Polistes dominula}

This field study was conducted in the Nelson-Tasman region of New Zealand in late summer, in February 2020, when wasp densities were high. Six sites were chosen to quantify the predation pressure of paper wasps on monarch caterpillars: two suburban, two coastal and two forest. Both suburban sites were residential areas containing a house and garden area. Both gardens contained a mix of native and exotic shrubs, flaxes and herbaceous plants, with mature trees along the back boundary of the properties. Coastal sites were within $100 \mathrm{~m}$ of the high tide line and lacked any permanent anthropogenic structures. These coastal sites were comprised of a mix of sedges, herbaceous plants, shrubs and grasses. One of the coastal sites contained plastic plant protectors as part of a local conservation programme, which both Polistes spp. were observed to utilize as nesting sites. Forest sites were $50 \mathrm{~m}$ in from the forest 
edge, with a canopy cover of $>50 \%$ and both sites comprised a mix of exotic and regenerating native forest. The suburban sites either contained or were in close proximity to, several self-sown Gomphocarpus plants. There did not appear to be any milkweeds growing in close proximity to any coastal or forested sites.

Each study site was roughly $700 \mathrm{~m}^{2}$ in size. Wasp nest densities of both $P$. dominula and $P$. chinensis were estimated by thoroughly searching within the chosen site and recording the nests found and counting the number of wasps per nest. This estimate was then scaled to give an estimate of wasp densities per $1,000 \mathrm{~m}^{2}$ for each site. Previous research has found the foraging distance of Polistes spp. to be roughly $150 \mathrm{~m}$ (Dew \& Michener, 1978), so calculations of wasp densities in the area could be an underestimate of the number of wasps within range of the experiment.

Monarch caterpillars were used for this experiment as their larval stage occurs when paper wasp densities are high. They are also a common species in suburban habitats of New Zealand (Wise, 1980). The caterpillars used in this experiment were reared from eggs gathered in situ from milkweeds in the Nelson region and kept safe from predators within a netted enclosure. At the time of the experiments, there was a wide range of caterpillars across all instars. To discover the effect of caterpillar size on survival, the caterpillars were separated into two groups. Caterpillars from the $2^{\text {nd }}$ through to early $4^{\text {th }}$ instar were classified as 'small' and late $4^{\text {th }}$ instar through to $5^{\text {th }}$ instar were classified as 'large'. In order to record caterpillar survival as accurately as possible, the experiment was carried out at two study sites per day across three days, rather than all six sites simultaneously. Two observers conducted the experiment, one at each site. To reduce the influence that variable weather conditions could have on results, experimental days were chosen when weather was predicted to be relatively sunny, with no rain, low winds and maximum temperatures of $21^{\circ} \mathrm{C}$ or higher.

Six potted milkweed plants were chosen for each site, three of which were covered in an insect-proof cloth as a control to exclude Polistes wasps. The plants used were between $71-95 \mathrm{~cm}$ tall. Five small and five large caterpillars were assigned to each individual plant. Caterpillars were placed on their respective plants an hour before the experiment to give them time to settle. Pairs of plants (one exposed and one control) were then placed within the study site with a spacing between plant pairs of at least $20 \mathrm{~m}$. These milkweed plants were monitored at the sites for six hours between the hours of 10:30-11:00 and 16:30-17:00 when wasps are observed to be actively 
foraging. Hourly counts of remaining caterpillars were recorded, as well as any additional observations of caterpillar mortality between these hourly intervals. Where possible, the cause of caterpillar mortality/absence was recorded.

The majority of caterpillars used in this experiment were too large for either Polistes spp. to remove in a single flight, so the wasp that initiated the attack would often return repeatedly to cut and remove a food bolus from its prey. If the exact moment of attack on a particular caterpillar was not observed, but a wasp was seen to be collecting a food bolus from the caterpillar, this wasp was assumed to be the cause of death. On occasion, $5^{\text {th }}$ instar caterpillars were found on the ground or vegetation in close proximity to their respective milkweed plant. This behaviour was observed during both trials for all habitat types and was likely driven by the individuals' need to pupate. If discovered, the caterpillars were returned to their plant. The wasp species, size and nest location were noted to determine how many wasps successfully predated caterpillars on a particular plant. It is possible to identify individual wasps of $P$. dominula based on features such as facial (Tibbetts \& Lindsay, 2008) and thoracic markings, wasp size and direction of flight path. The identification of individual wasps was assessed predominantly by looking at markings on the face, as the size, shape and number of black spots on the clypeus of $P$. dominula are highly variable (Fig. 3.2) (Tibbetts \& Dale, 2004). Two trials of this experiment were conducted on consecutive weeks: trial 1, 9-14 February and trial 2, 16-20 February 2020.

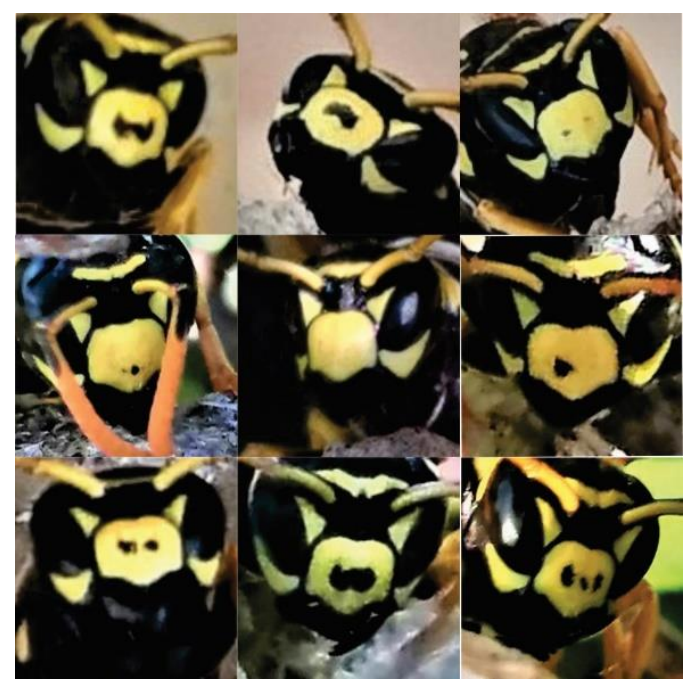

Fig. 3.2. Photos exhibiting the high variation in black spot patterning on the clypeus of $P$. dominula, which can be used to identify individual wasps. Photo credit: Rose McGruddy. 
Experiment 2 - Cascading effects of Polistes dominula predation on host plant fitness

The cascading effects of $P$. dominula on milkweeds was tested in a field experiment from January to March 2020. This experiment was done simultaneously in both the Nelson region, where $P$. dominula is present, and the climatically similar Wairarapa region $\left(40.9449^{\circ} \mathrm{S}, 175.6690^{\circ} \mathrm{E}\right)(\mathrm{NIWA}, 2016)$, where $P$. dominula is yet to establish. Ideally, the two regions would have been in closer proximity, however, this was not possible with the current distribution of $P$. dominula. Three suburban sites were selected within each region. Five milkweed plants were placed within each site, two of which were controls covered by insect-exclusion nets to prevent $D$. plexippus butterflies from laying their eggs and to exclude wandering caterpillars. This gave a total of 15 plants in $P$. dominula occupied areas and 15 in areas where $P$. dominula was absent. The milkweeds were in free-standing pots, placed in garden areas where they would receive full sun. Groundcover in these gardens varied both between and within sites, ranging from grass and soil to bark or gravel. Height of the surrounding vegetation varied, with some milkweeds standing alone, metres from other vegetation, whilst others were within proximity of mature trees upwards of $4 \mathrm{~m}$ tall. Plants were watered every two to three days as needed.

In both regions the exposed milkweed plants were available for the natural colonisation of $D$. plexippus. Resulting caterpillars can cause substantial damage to their host plant through the consumption of leaves, stems and flowers. The cascading effects of $P$. dominula on the host plant were therefore measured through changes in plant growth (height and leaf number) and reproductive output (number of flowers per plant) at the end of eight weeks. A measure of seed pods would have given a better estimate of reproductive output, but constraints of the experimental design prevented this, as the insect-exclusion nets used for the control plants excluded both caterpillars and pollinators.

To control for as much variation in plant changes as possible between the two regions, all 30 plants were transplanted into $20 \mathrm{~cm}$ pots containing the same brand of potting mix. Prior to the experiment, any invertebrate inhabitants that could confound results, such as aphids or monarch eggs, were removed from all plants. Plant height, leaf number and flowers were counted for each individual plant before the experiment. The initial height of plants from the soil line within each pot ranged between $75-102 \mathrm{~cm}$. The initial number of leaves per plant ranged from 86 to 257. The flowers of $G$. 
physocarpus are primarily white and grouped in drooping umbels of approximately eight flowers. No plants were flowering prior to the experiment.

\section{Statistical analysis}

Statistical analyses were conducted in R 3.6.0 (R Development Core Team, 2020). Data from the annual butterfly survey was grouped according to the year the summer season began. As butterfly numbers tend to fluctuate based on each species life cycle, butterfly counts from each walk were averaged for each month of December, January, February and March for comparison between species. In the summer beginning in 2014 , only one weekly survey was conducted for the months of February and March, which was presented as the average for that month. The summer of 2015 is estimated to be the time when $P$. dominula was introduced and became abundant in the region. For a statistical comparison of butterfly abundance before and after the establishment of $P$. dominula, the dataset was split. Butterfly counts from 2009-2014 were placed into one group and the counts from 2015-2019 were placed in another. To ensure approximate normality of the data, counts for $D$. plexippus, $P$. rapae and $Z$. labradus were square-root transformed before they were analysed using ANOVA.

The results of the first experiment investigating the effects of $P$. dominula predation on monarch caterpillars did not differ significantly between trial 1 and trial 2, so the datasets were combined for analysis. Monarch caterpillar survival was investigated using the 'survival' (Lin \& Zelterman, 2002) and 'survminer' (In \& Lee, 2019) packages to generate Kaplan-Meier plots to visualize survival curves, with differences between these curves analysed using pairwise log-rank tests (Jager et al., 2008). Not all instances of caterpillar absence could be attributed to death, as there were a small number of cases where caterpillars were simply absent from the plant, with no evidence of predation (caterpillar remains, haemolymph on leaves, etc.). The majority of these unexplained absences involved caterpillars that were in their $5^{\text {th }}$ instar stage that had likely left the plants in search of a suitable place to pupate. In the absence of contrary evidence, however, these absences were still coded as a death event in the survival analyses. Logistic regression was used to assess the relationship between estimated densities of Polistes spp. and caterpillar survival. The indirect effects of $P$. dominula on changes in host plant height, leaf number and reproductive output were 
analysed using a one-way ANOVA, with data tested to ensure normality. Pairwise comparisons between groups were conducted using Tukey's post hoc analysis.

\section{Results}

Annual survey of butterfly abundance

There was a significant decline in butterfly abundance across all three butterfly species (D. plexippus, $P$. rapae and Z. labradus) from the summer beginning in 2015 (Fig. 3.3a-c). The grouped average butterfly abundance for the summers of 2015-2019 was significantly lower than the grouped average butterfly abundance for the summers of 2009-2014. There was an overall decrease of $66 \%$ for $D$. plexippus $\left(F_{1,152}=79.89, P\right.$ $<0.001)$, 54\% decrease for $P$. rapae $\left(F_{1,152}=61.95, P<0.001\right)$ and $87 \%$ decrease for $Z$. labradus $\left(F_{1,152}=26.85, P<0.001\right)$. A small spike in abundance can be observed in February and March of the 2019 summer for both $D$. plexippus and $P$. rapae, which may be indicative of early stages of population recovery for these two species. To consider climate as an explanation for changes in abundance, further analyses were conducted investigating the possible effects of rainfall and air temperature on butterfly numbers. These climate variables did not differ significantly in the periods before and after $P$. dominula introdution $(P \geq 0.199)$ so they are unlikely to have affected the patterns of observed butterfly abundance. The full results of this climate analysis are presented in Appendix B (Tables B1 \& B2, Figures B1 \& B2). 
(a)

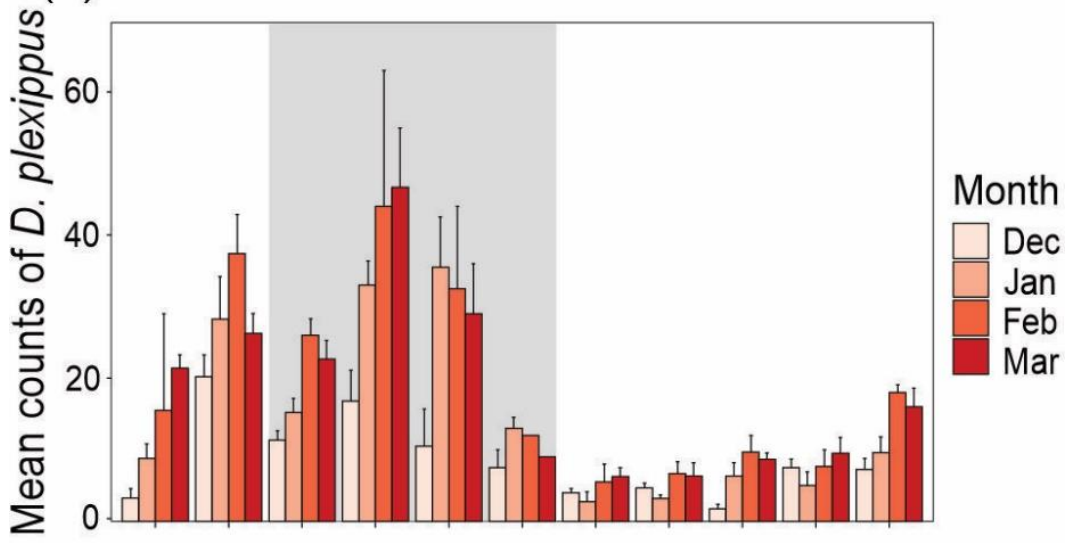

(b)

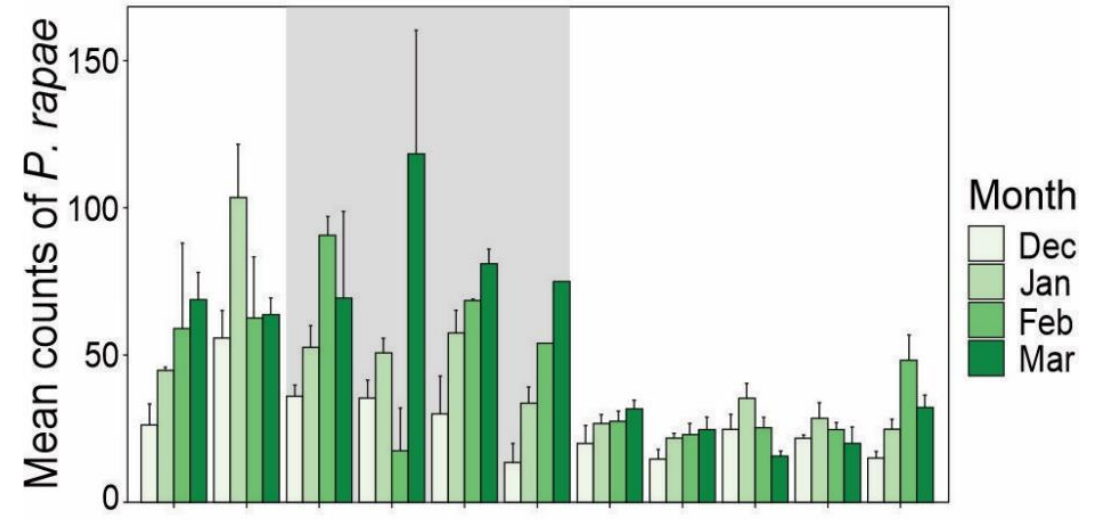

(c)

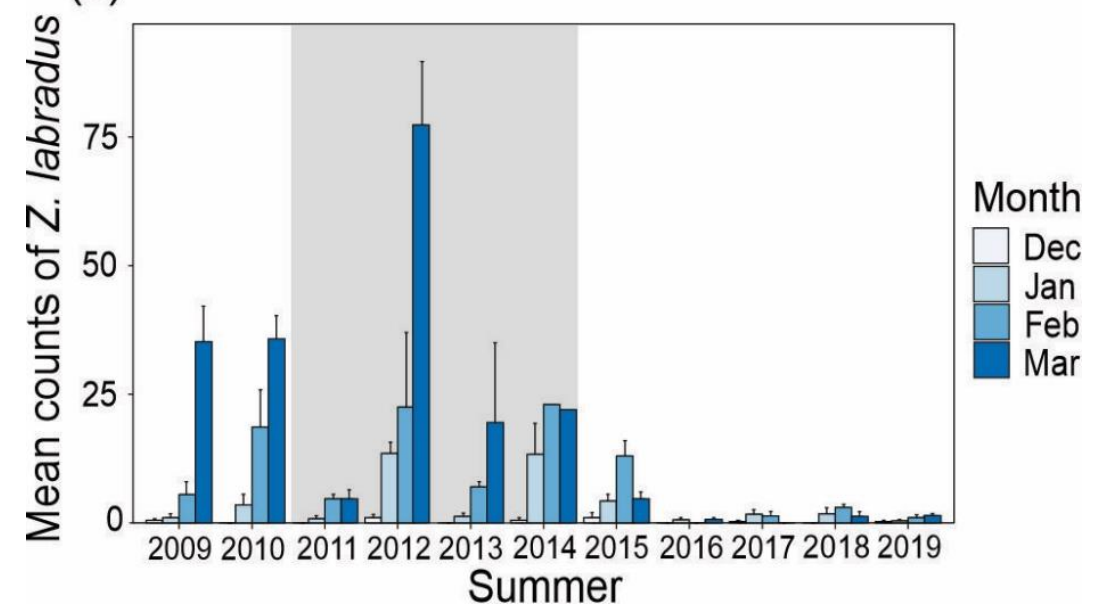

Fig. 3.3. Data from an annual survey in Nelson showing mean (+ 1 SE) butterfly abundance for three local species: (a) Danaus plexippus, (b) Pieris rapae and (c) Zizina labradus. Butterfly abundance is presented from the months of December through to March over 11 summers. The area highlighted in grey from 2011-2014 is the likely timeframe of $P$. dominula invasion in Nelson, New Zealand. 
Predation of caterpillars by Polistes dominula

Predation by $P$. dominula was the reason for $85 \%$ of monarch caterpillar deaths on milkweed plants across both trials (Fig. 3.4). Predation by $P$. chinensis explained just $5 \%$ of caterpillar deaths, while the cause of $9 \%$ of caterpillar absences was unknown. During trial 1 at a suburban site, a weka (Gallirallus australis), a bird native to New Zealand, pecked and killed two monarch caterpillars, but did not consume them, accounting for the final $1 \%$. Caterpillar survival rates differed significantly for all three habitat types (Pairwise log-rank test, $P<0.05$, Fig. 3.5). Overall, caterpillar survival in suburban areas was the lowest, with only $45 \%$ remaining after just six hours of exposure. Survival in coastal areas was higher than suburban, with $64 \%$ of caterpillars surviving the trial. Forest sites had the highest survival rates, with $96 \%$ of caterpillars found to still be on the plant after six hours. Of the small proportion of caterpillars that were unaccounted for in the forest sites, predation was not observed to be the cause of absence.

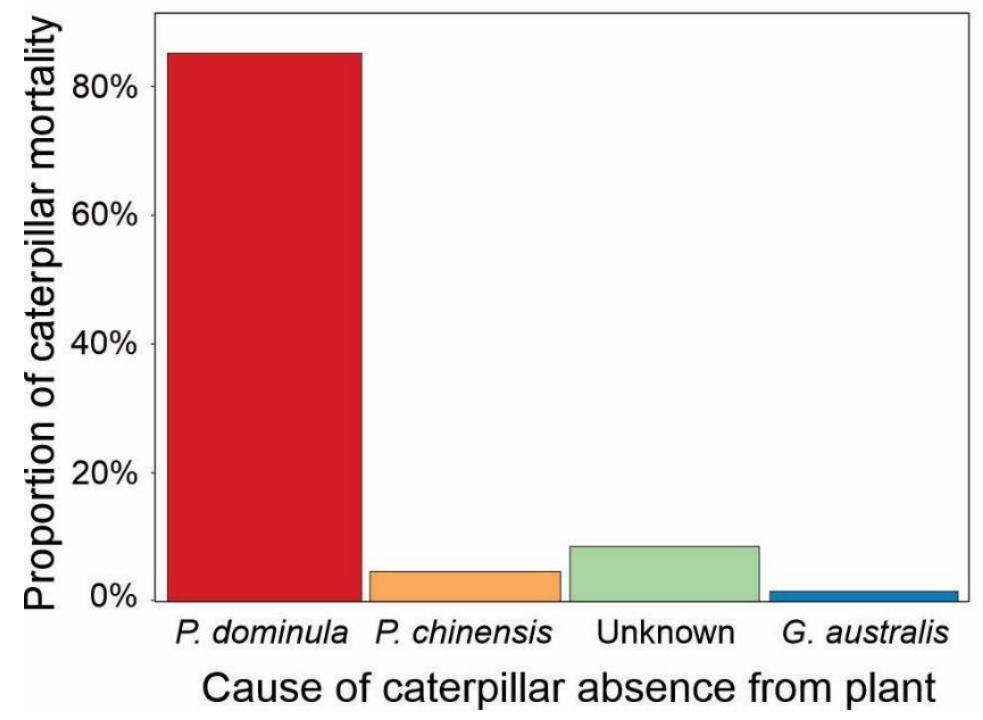

Fig. 3.4. A summary of the cause of death/absence of monarch caterpillars for three habitat types combined (suburban, coastal and forest) over a 6-hour time period. The total mortality of caterpillars shown is for two trials. 
Fig. 3.5. Kaplan-Meier survival estimates $( \pm 95 \% \mathrm{Cl})$ on the survival of monarch caterpillars based on habitat type (suburban, coastal or forest) over a 6-hour time period. Survival curves are the combined results of two trials ( $n=120$ for each habitat type). Pairwise log-rank tests were used to compare survival of caterpillars in each type of habitat.

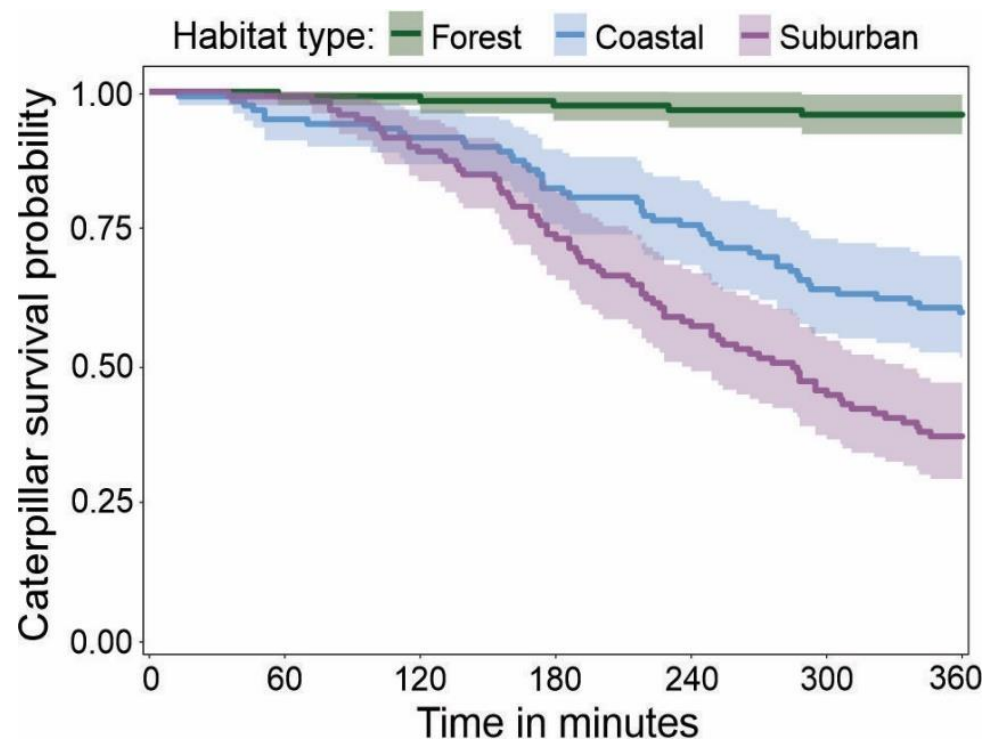

The probability of caterpillar mortality increased significantly as densities of $P$. dominula increased (estimate $=0.011$, SE $=0.002, P<0.001$ ). Suburban sites had the highest $P$. dominula densities, with an average of $104 \pm 2.6$ wasps per $1,000 \mathrm{~m}^{2}$ (Table B3). Densities of $P$. dominula in coastal sites were lower, with an estimate of $65 \pm 5.5$ wasps per $1,000 \mathrm{~m}^{2}$. Estimated densities of $P$. chinensis were not significantly associated with the probability of caterpillar mortality (estimate $=-0.02, \mathrm{SE}=0.012, P$ $=0.119)$. The average densities of $P$. chinensis in the suburban and coastal sites were $3 \pm 0.1$ wasps per $1,000 \mathrm{~m}^{2}$ and $22 \pm 0.5$ wasps per $1,000 \mathrm{~m}^{2}$, respectively. No nests of either $P$. dominula or $P$. chinensis were found within the forest sites, and therefore the densities of paper wasps in these areas were recorded as zero.

Small caterpillars had a lower chance of survival than large caterpillars at sites occupied by $P$. dominula, as small caterpillars constituted $61 \%$ of all deaths (log-rank test, $X^{2}=13.5 ; P<0.001$, Fig. 3.6). Large caterpillars were frequently observed to rear and thrash their bodies when attacked by $P$. dominula, sometimes deterring the wasp sufficiently for it to search elsewhere. Small caterpillars were not as successful in deterring wasps when exhibiting similar behaviour.

Of plants where $P$. dominula discovered caterpillars, $42 \%$ were discovered by only one wasp. That individual would continue to return to the plant repeatedly to search for more caterpillars throughout the day. The maximum number of wasps to discover caterpillars on a single plant within the six-hour timeframe was five. In instances where 
multiple wasps found a plant, they often left in different directions, indicating they were from different nests.

Fig. 3.6. Kaplan-Meier survival estimates $( \pm 95 \% \mathrm{Cl})$ of monarch caterpillars in areas occupied by the wasp $P$. dominula, based on caterpillar size over a 6-hour time period. Survival curves are the combined results of two trials $(n=240)$. A log-rank test was used to compare survival of small caterpillars $\left(2^{\text {nd }}-\right.$ early $4^{\text {th }}$ instar) with that of large caterpillars (late $4^{\text {th }}-5^{\text {th }}$ instar).

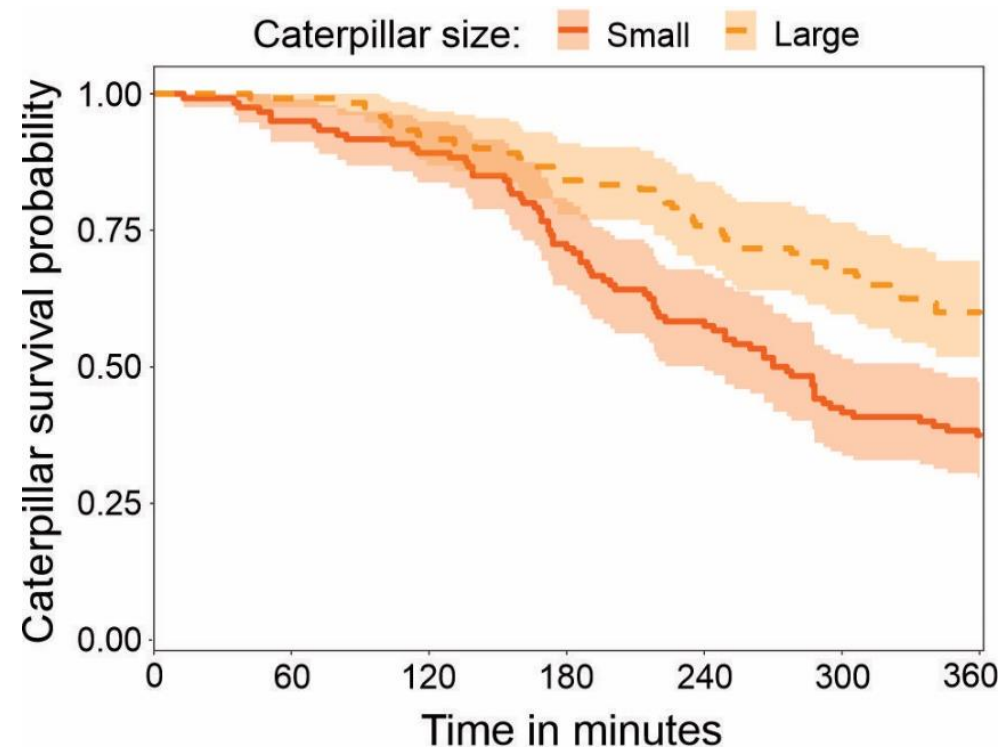

Cascading effects of Polistes dominula predation on host plant fitness

In the absence of the predatory $P$. dominula, monarch caterpillars significantly impacted milkweed growth (Fig. 3.7a), with the height of exposed plants increasing by only $3 \%$ on average. This change in height differed significantly to the observed height increase of $42 \%$ for the associated control plants which excluded caterpillars completely ( $P<0.001$, one-way ANOVA, Tukey's post hoc). In the presence of $P$. dominula, predation of monarch caterpillars was so effective at reducing plant damage that changes in plant height did not differ significantly between the increase of $35 \%$ for the exposed treatment and $38 \%$ for the associated control ( $P=0.944$, one-way ANOVA, Tukey's post hoc). Changes in height for exposed plants in $P$. dominula occupied areas also did not differ significantly to the changes in height observed for control plants in areas without this wasp $(P=0.786$, one-way ANOVA, Tukey's post hoc).

Monarch caterpillars substantially reduced the number of leaves on exposed milkweeds in areas where $P$. dominula were absent (Fig. 3.7b), with an average leaf decrease of $63 \%$, which differed significantly from the average leaf increase of $57 \%$ 
for the associated control plants ( $P<0.001$, one-way ANOVA, Tukey's post hoc). Again, the strong, indirect effect $P$. dominula had on reducing plant damage caused by monarch caterpillars meant changes in leaf number did not differ significantly between the $96 \%$ increase for the exposed treatment and $96 \%$ increase for the associated control ( $P=0.993$, one-way ANOVA, Tukey's post hoc). There was also no significant difference in leaf changes between exposed plants in areas with this wasp and control plants in areas without $P$. dominula $(P=0.996$, one-way ANOVA, Tukey's post hoc). It should be noted that minor leaf damage was observed on leaves in the presence of $P$. dominula, indicating that caterpillars were hatching and consuming plant material. However, these caterpillars appeared to be removed before they could cause extensive damage to plant growth.

Fig. 3.7. Relative changes in milkweed plant (a) height, (b) leaf number and (c) reproductive output in response to the presence or absence of the predatory wasp $P$. dominula. Exposed treatments allowed for monarch butterflies to lay eggs on milkweeds and for resulting caterpillars to feed on the host plant. Control treatments were plants covered by bug-exclusion nets to exclude monarch adults and caterpillars from having access to the milkweed plant, preventing herbivory. (a)
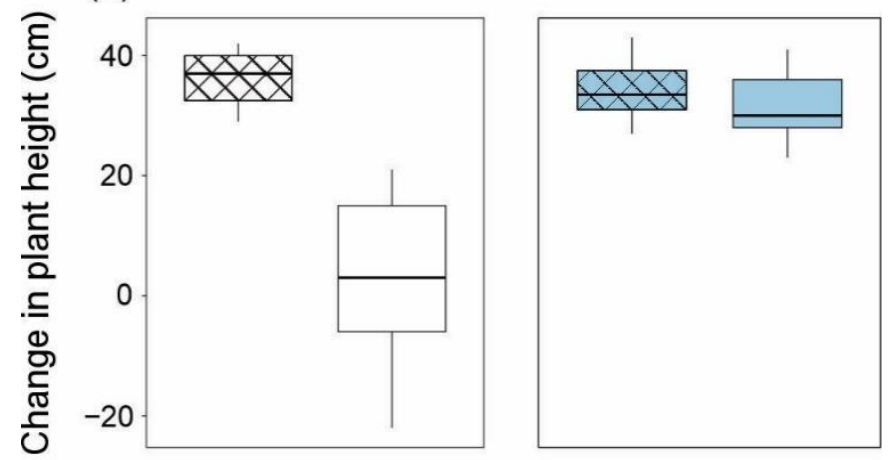

(b)
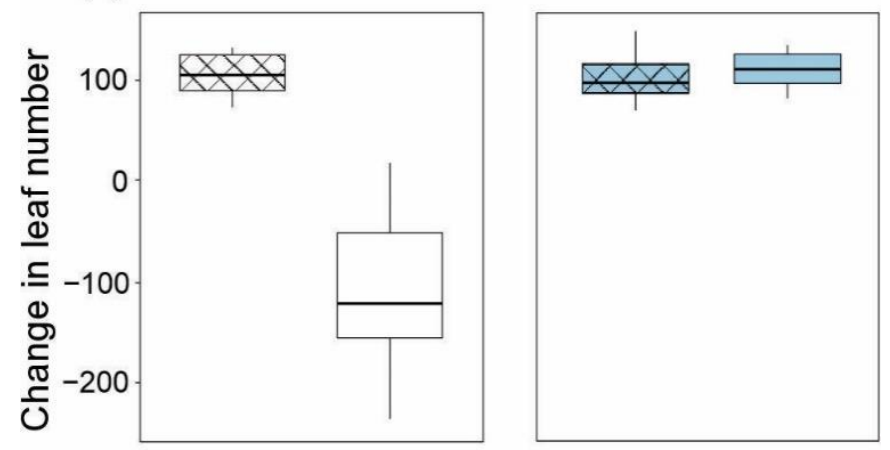

(c)

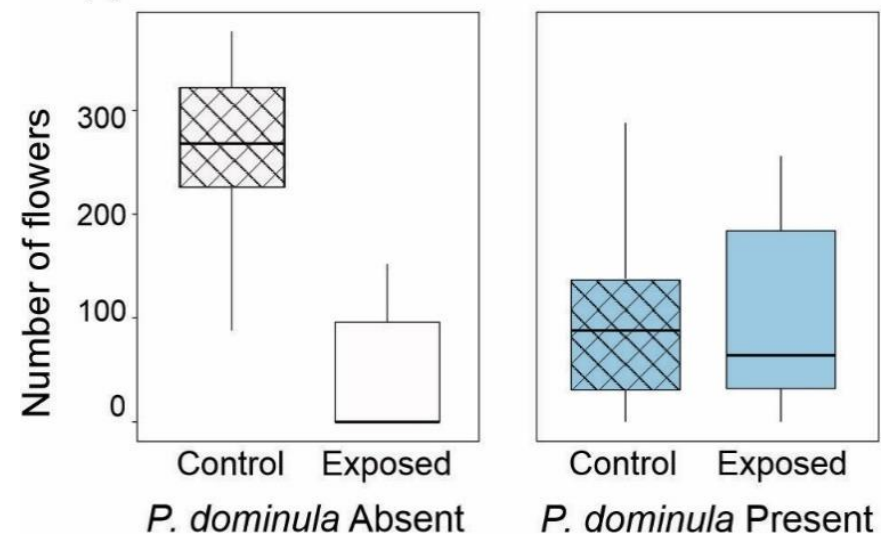


Exposed milkweeds in areas without $P$. dominula produced an average of $29.8 \pm 19.9$ flowers, with control plants in the area producing an average of $259 \pm 41.5$ flowers. The difference in flower number between the two treatments was significant $(P<$ 0.001, one-way ANOVA, Tukey's post hoc, Fig. 3.7c). This result shows that caterpillar herbivory likely had a strong enough effect to negatively impact plant reproduction. The number of flowers per plant did not differ significantly between exposed milkweeds in areas where $P$. dominula were present relative to the associated control $(P=0.999$, one-way ANOVA, Tukey's post hoc). The average number of flowers on plants for the exposed and control treatments in the presence of $P$. dominula were $99.6 \pm 30.7$ and $105 \pm 43$, respectively. This similarity between exposed and control treaments suggest $P$. dominula can remove caterpillars effectively enough to prevent herbivory from having significant, detrimental effects on plant reproduction. There were roughly three times the average number of flowers on exposed plants in $P$. dominula occupied areas (99.6 \pm 30.7$)$ compared to exposed plants in areas where $P$. dominula were absent (29.8 \pm 19.9$)$, however, the difference in flowers produced was not significant $(P=$ 0.569, one-way ANOVA, Tukey's post hoc). There was a significantly greater number of flowers for the $P$. dominula absent control treatment compared to both treatments where $P$. dominula were present (Tukey's post hoc, $P<0.05$ ). Many plants require a minimum number of leaves for floral intitiation (Holdsworth, 1956), as the production of reproductive structures is energetically costly. The milkweed plants in the $P$. dominula present area had fewer leaves on average (113 \pm 5.2 initial leaves) prior to the experiment than plants in the area without this wasp (179 \pm 12.7 initial leaves). It is reasonable, therefore, to assume that the plants in the Nelson region had less flowers as they likely reached the minimum leaf number required to reproduce at a comparatively later stage.

\section{Discussion}

We found that the invasive wasp $P$. dominula can exert a predation pressure strong enough to initiate a trophic cascade. The removal of monarch caterpillars as a result of $P$. dominula predation significantly reduced herbivore load. This predation in turn yielded a significant increase in plant height and foliage for plants in the presence of $P$. dominula compared to plants in areas where this wasp was absent. These results were in accordance with predictions for plant growth, as monarch caterpillars consume 
the leaves and stems of the plant, causing substantial damage to their host. Whilst the presence of $P$. dominula did not lead to a significant difference in flower production compared to exposed milkweeds in areas without this predator, the similarity in the number of flowers per plant compared to control plants in the Nelson region suggest that $P$. dominula is having a strong effect on reproductive output. Ideally, reproductive output would have been quantified as seed pod production rather than flowers for this study, but the nets used on control plants to exclude monarch caterpillars also excluded pollinators. However, our observations of self-sown, older milkweed plants in the region with $P$. dominula found these plants to be heavily loaded with seed pods. Therefore it seems that the increased flowering level results in increased seed production.

Increases in $P$. dominula densities were found to significantly decrease the probability of caterpillar survival. Densities of $P$. dominula were highest in suburban areas, which was in accordance with findings of previous research that these wasps prefer to nest on anthropogenic structures (Roets et al., 2019). A higher rate of caterpillar predation in urban gardens was observed in a similar study investigating the predatory effects of $P$. dominula on monarch caterpillars in differing habitat types (Baker \& Potter, 2020). Coastal areas were found to contain comparatively fewer $P$. dominula nests than suburban areas, which appeared to be reflected in the lower mortality rates of caterpillars in these areas. No nests of either $P$. dominula or $P$. chinensis were found within forest habitats. This result was unsurprising as a negative correlation has been observed between Polistes and canopy cover (Schmack et al., 2020). Caterpillar loss in forest areas was not observed to be a result of predation and was likely due to $5^{\text {th }}$ instar individuals leaving the plant to pupate. However, we cannot rule out the possibility of predation by another species, as predatory Vespula spp. have also established in New Zealand and been proven to significantly deplete Lepidopteran populations in forest habitats (Beggs \& Rees, 1999). The invasive paper wasp $P$. chinensis, which is documented as a predator of monarch caterpillars (Ward \& RamónLaca, 2013), accounted for a relatively small proportion of caterpillar deaths in suburban and coastal areas, perhaps due to its lower abundance compared to $P$. dominula.

Our study found $P$. dominula densities to significantly impact monarch caterpillar survival rates, yet surprisingly few wasps actually discovered, and killed, caterpillars. 
On average, only one wasp found, and succesfully hunted prey on an experimental milkweed. This wasp then appeared to return to the plant repeatedly throughout the day, taking more caterpillars. The maximum number of wasps to successfully predate upon caterpillars on any individual milkweed plant during a 6 hour trial was five. One explanation for this finding is the lack of recruitment behaviour in many social wasp species (Jeanne et al., 1995; Richter, 2000). Therefore, the discovery of caterpillars seemed to be an outcome of chance foraging success by an individual wasp.

Large caterpillars (late $4^{\text {th }}$ to $5^{\text {th }}$ instar) had a lower rate of mortality relative to small caterpillars ( $2^{\text {nd }}$ to early $4^{\text {th }}$ instar). This lower mortality is unsurprising based on observations in the field of large caterpillars thrashing about or dropping to the ground when touched by $P$. dominula, resulting in the wasp searching elsewhere. Similar observations were made in previous studies focused on the predation of monarch caterpillars by $P$. dominula (Baker \& Potter, 2020; Rayor, 2004). These findings suggest that if a caterpillar is able to survive through earlier instars, there is a size threshold where they are more likely to escape predation.

The results from the annual butterfly survey not only provide evidence that monarch butterfly populations have declined significantly since the establishment of $P$. dominula, but they show a decline in other Lepidopteran populations as well. One of the populations in decline was the common blue butterfly, Zizina labradus which, like the monarch butterfly, is a self-introduced species in New Zealand (Gibbs, 1980). Declines in populations of Pieris rapae (white butterfly) following the arrival of $P$. dominula is considered to be a beneficial outcome, as the caterpillars of this invasive pest eat the leaves of cabbage, broccoli and other brassica vegetables. Paper wasps have been recommended as control agents against $P$. rapae, as predation by Polistes spp. has been found to significantly increase cabbage weight (Gould \& Jeanne, 1984).

The butterfly surveys coupled with results from our experiments give a compelling case that $P$. dominula exert a strong predation pressure on Lepidopteran species in New Zealand, which can indirectly influence lower trophic levels. As $P$. dominula is a generalist predator, it is possible that this wasp could be impacting not only the relationship between monarchs and their host, but also the host plants of other prey species. Invasive species have the capacity to reach high abundances within their invaded ranges. This phenomenon is often explained by factors such as enemy release (Torchin et al., 2003). High levels of abundance in addition to their exploitation 
of novel prey is what makes the impact of invasive predators so devastating (Beggs \& Rees, 1999; Piovia-Scott et al., 2017).

The upward trend in 2019 for both monarch and cabbage white butterflies suggests butterfly populations may be recovering. It is not uncommon for invasive insect populations to crash following an initial outbreak and population boom (Lester \& Gruber, 2016). The population decline of an invasive species is often attributed to causes such as parasites, disease outbreaks, competition or resource availability (Strayer et al., 2017). The slight increase in butterfly abundance over the most recent summer could be an indicator that $P$. dominula is experiencing a population decline in that area. Even a small decline in wasp abundance may be sufficient to allow butterfly abundance to increase.

It has been observed that exotic species are capable of facilitating the invasion and spread of other exotic species (Relva et al., 2010). In addition to their positive, indirect effects through predation, $P$. dominula might also be having a direct, positive effect as a pollinator of milkweeds (Rafferty \& Ives, 2012). Several species of milkweeds have been introduced to New Zealand, and in addition to G. physocarpus, the other two most common milkweed species are G. fruticosus and Asclepias curassavica. The milkweed Asclepias tuberosa, known in North America as the "butterfly weed", is not imported to New Zealand for fear of it spreading and becoming an invasive weed (MPI, 2018). The abundance of milkweeds in New Zealand is currently controlled by the intense herbivory of monarch caterpillars (Wise, 1980). Herbivore removal can potentially cause harm if there are no other regulating factors in place to control exotic plant species (Zavaleta et al., 2001). Released from this regulation by the indirect effect of $P$. dominula predation, $G$. physocarpus and other milkweed species could become so abundant as to be perceived as invasive weeds. More definitive research would need to be conducted to test this, but initial observations suggest that one invasive pest species may have created another. 


\section{Chapter 4: General discussion}

In this thesis, I investigated the abundance, nesting ecology and predatory impacts of $P$. dominula in Nelson, New Zealand. I investigated the abundance and nesting behaviour of $P$. dominula and the congener $P$. chinensis that established in New Zealand decades earlier, as a comparison to gauge the success of $P$. dominula at its early stages of invasion. This investigation was achieved by monitoring nests in the field, recording their growth and survival over two reproductive cycles and recording the nesting behaviours that appeared to have contributed to their success. I determined the habitat preference of both species, which has implications for communities that host the highest abundance of these predators. Additionally, when $P$. dominula were not observed to occupy forest habitats, to determine whether this absence was due to an inability to thrive, I translocated nests into these areas and recorded colony growth and survival.

I measured the strength of the predation pressure exerted by $P$. dominula on invertebrate prey by placing monarch caterpillars into the field and recording their fate. Additionally, I presented results from an annual butterfly survey that spanned six years before the discovery of $P$. dominula and the five years following its known presence, showing a decline of butterfly abundance in Nelson since the invasion of $P$. dominula. Finally, I tested whether the predation pressure exerted by $P$. dominula was strong enough to have cascading effects on the host plant of monarch caterpillars. The results presented in this thesis should inform and guide biodiversity management decisions and aid our understanding of how invasive species affect host communities.

\section{The abundance, nesting ecology and survival of Polistes dominula}

The ecology and behaviour of invasive organisms can differ across ranges, which has implications for the level of impact the invader has on native communities (Hozumi et al., 2015; Lester \& Beggs, 2019). Knowledge of the ecology of an invasive organism is essential for effective population management (Caesar, 2005; Lester \& Beggs, 2019; Nuñez et al., 2017). In chapter two, I studied the abundance, nesting ecology and survival of the invasive wasp $P$. dominula in Nelson, New Zealand. I found that $P$. dominula was most abundant in suburban habitats. The rate of nest survival for $P$. 
dominula was particularly high in these areas, where this species utilized manmade substrates as nesting sites. The preference and success of $P$. dominula in suburban habitats was anticipated, as $P$. dominula has been observed to prefer these habitats in other areas of this wasp's range (Gamboa et al., 2005; Perez-Bote \& Mora-Rubio, 2020; Roets et al., 2019). Urban areas may create warmer environments in temperate regions for invasive wasps like $P$. dominula that originate from warmer climates (Sorvari, 2018). As suburban areas had the highest abundance of $P$. dominula, communities in these environments are most at risk of being impacted by this new exotic wasp species. Many of the invertebrates affected in these areas will be exotic species, like the cabbage white butterfly (Pieris rapae), the control of which is a desirable outcome for some residents. However, there will be native species, like the yellow admiral butterfly (Vanessa itea Fabricius), and endemic red admiral butterfly (V. gonerilla Alfken), at risk of predation by $P$. dominula. In coastal habitats, $P$. dominula was comparatively less abundant than in suburban habitats, however, communities in these areas will also be affected. Endemic species in these areas likely to be influenced include the threatened copper butterfly, Lycaena ianthina Salmon, and the conservation-dependent Kiwaia sp. (yet to be assigned a scientific name) found only in Cloudy Bay of the upper South Island (Hoare et al., 2017). Evidence for $P$. dominula predation of several of these butterfly species can also be seen in the findings from a diet analysis of $P$. dominula in Nelson (Howse et al., 2021).

Neither $P$. dominula nor $P$. chinensis were observed to nest within forest habitats in this study. Nests of $P$. dominula translocated into these areas either died or did not grow over the course of the experiment, contrasting to the nests placed in coastal and suburban habitats. The lower temperatures in the shade of the forest canopy were likely to be a factor contributing to the inability of this wasp to thrive. Sun-warmed sites have been found to contain more Polistes spp. nests, with faster brood development and the earlier emergence of workers (Jeanne \& Morgan, 1992). The findings of the translocation experiment confirm that native and exotic forests are unlikely to be infested with $P$. dominula, which has management implications. The majority of New Zealand's native and endemic invertebrate species are forest-dwellers (Watt, 1975), so species in these areas, such as the rare, endemic, forest ringlet butterfly (Dodonidia helmsii Butler) (Hoare et al., 2017), are not likely to be impacted by this wasp. 


\section{The direct impacts of Polistes dominula}

Invasive predators can have significant impacts on prey populations within their new range (Beggs \& Rees, 1999; Potter-Craven et al., 2018; Toft \& Rees, 1998). In chapter three, I found $P$. dominula exerted a strong predation pressure on caterpillars of the monarch butterfly (Danaus plexippus). I expected $P$. dominula to be the primary cause of monarch caterpillar mortality, as Nelson residents had reported a substantial drop in monarch populations since the establishment of $P$. dominula. Residents also told me they had seen paper wasps attack and eat monarch caterpillars. The findings from the annual butterfly survey in Nelson demonstrated a decline of monarchs and other local butterfly populations, providing further support that $P$. dominula was having a strong impact on local invertebrate species. Diet analyses on the gut contents of $P$. dominula larvae in coastal areas of Nelson have found butterflies are not the only insects being predated upon. Samples I helped Matthew Howse collect for his research on the diet of $P$. dominula in Nelson, New Zealand, showed that this predator has a very wide prey range (Howse et al., 2021). In addition to numerous moth and butterfly species being found in the gut contents of wasp larvae, other invertebrates present included; cicadas (Kikihia spp. and Amphipsalta spp.), beetles, flies, mantids (Orthodera sp.), spiders (Cryptachaea spp.), leafhoppers and crickets.

\section{The cascading effects of $P$. dominula}

Originally, the 'trophic cascade' concept was developed as a foundational ecological theory, allowing for a better understanding of food webs and community dynamics, with a particular focus on the cascading effects of predators. Trophic cascade theory has since been developed so that it can be applied to the management and conservation of ecosystems (Bamber et al., 2020; Ripple \& Beschta, 2012; Ripple et al., 2016). In this study, the indirect, cascading effects of $P$. dominula on the milkweed host plants of monarch caterpillars appeared to be strong enough to impact plant fitness. As $P$. dominula is a generalist predator, a diverse group of invertebrate species is included in their diet (Cervo et al., 2000; Howse et al., 2021). It is therefore likely that multiple host plants of invertebrates are influenced by the presence of this invasive wasp. As invertebrates serve a wide range of ecological functions, significant reductions in certain populations could have detrimental knock-on effects for the wider 
community. Previous studies focusing on the role of insect predators in trophic cascades have predominantly been conducted in agricultural systems, as a means of finding more effective biocontrol agents to manage herbivorous crop pests (Ali et al., 2018; Gould \& Jeanne, 1984; Southon et al., 2019). The research conducted in this thesis makes an important contribution to the field of ecology, as it offers insight into the impacts of an invasive, insect predator from a biodiversity management perspective. For example, my study indicates that forest-dwelling species such as the forest ringlet butterfly (Dodonidia helmsii) are unlikely to be affected by $P$. dominula. Species of conservation interest restricted to suburban or coastal sites, in contrast, are much more likely to experience predation by this wasp. Similarly, trophic cascades induced by this predator would be possible in suburban or coastal, but not forest, habitats.

\section{Future directions and management of Polistes dominula}

Further information on the ecology and impacts of $P$. dominula in New Zealand would be useful for its management. This study demonstrated that $P$. dominula exerts a strong predation pressure on monarch caterpillars, but as a generalist predator, this wasp is likely impacting a wide range of invertebrate species. Diet analysis of $P$. dominula has been conducted in coastal habitats (Howse et al., 2021), yet a similar analysis for wasp populations in suburban habitats where this wasp is most abundant could be useful in identifying which invertebrate species could be under threat. As a primarily suburban species, $P$. dominula may prove beneficial in these areas, as this wasp could predate upon herbivorous pests in gardens and vegetable patches, and thus be of benefit for pest control (Lester, 2018; Sumner et al., 2018), but there is also the potential for native species that colonise these areas to be influenced. Further research into the invertebrate species impacted by $P$. dominula would better inform biodiversity and conservation management.

The current confirmed distribution of $P$. dominula includes the upper part of the South Island of New Zealand, with reports of the distribution of this wasp spreading as far South as Alexandra (Howse et al., 2020). The only reported North Island sightings are from Auckland, although this is yet to be confirmed. It is possible $P$. dominula is already present in other areas throughout New Zealand and has been misidentified as its 
longer-established congener, P. chinensis. As Nelson has a port and is the area where $P$. dominula is believed to have been the longest, in addition to the preference of this wasp to nest on anthropogenic structures, $P$. dominula was likely introduced to New Zealand via a shipping container. Predictive modelling has found the vast majority of human-habited areas of New Zealand to be climatically suitable for this wasp to establish (Howse et al., 2020), so the spread of this species across New Zealand is likely to occur in the near future. The range expansion of this wasp is of concern for invertebrate species across the country, particularly moths and butterflies. Currently, Auckland is the only area of the North Island where P. dominula has been observed. If this wasp successfully spreads to the areas predicted in the model, there are several species of critically threatened moths inhabiting coastal areas of the North Island that would likely be impacted. An example of moths at risk if $P$. dominula spreads are two critically threatened subspecies of the Pimelea moth, Notoreas peronata, which are only found along the east coast of the North Island in areas predicted to be colonised by $P$. dominula (Howse et al., 2020).

The annual butterfly survey in chapter three exhibited a decline in the number of butterflies seen following the arrival of $P$. dominula, with some species affected more than others, yet none of the three species studied became locally extinct over the 11 years of surveying. This finding provides hope that some local species will be able to tolerate the predation pressure exerted by this wasp. There were even signs of a potential, slow population recovery for all three butterfly species in the most recently recorded summer of 2019. This small increase in numbers may just be a consequence of $P$. dominula experiencing a less-productive year, as colony growth and abundance of this wasp can fluctuate between years (Höcherl \& Tautz, 2015). Alternatively, $P$. dominula populations could be declining to some extent. Population 'booms' followed by sudden population declines of exotic species are frequently observed in invasive species (Cooling \& Hoffmann, 2015; Simberloff \& Gibbons, 2004; Wetterer et al., 2014). The 'boom-bust' concept is prominent in invasion biology and is fundamentally important to understanding and managing biological invasions (Strayer et al., 2017). The boom-bust phenomena has been observed in some populations of invasive ant populations across the globe (Lester \& Gruber, 2016). Argentine ant populations in New Zealand were found to have an average expected survival time of 14 years (Cooling et al., 2012). Invasive yellow crazy ant populations in Australia crashed within 
a timeframe of only five years (Cooling \& Hoffmann, 2015). Note that, however, not all populations of ants have declined in their invaded range (Lester \& Gruber, 2016; Menke \& Holway, 2020). To my knowledge, no previous publication has followed the long-term trends in $P$. dominula abundance or has documented a decline in their abundance after the invasion and colonisation of a new habitat. It will be interesting to follow the population dynamics of this wasp over the next decade.

Potential mechanisms behind the dramatic declines of invasive species are numerous and varied. Pathogens and parasites are one such mechanism found to drive population declines (Flory et al., 2011). Invasive species typically have lower genetic diversity as a consequence of bottlenecks associated with a comparatively small number of individuals invading a new area. This renders populations more susceptible to disease outbreaks. Competition with local species is another possible mechanism that could exclude an invasive species, particularly smaller populations as they have been found to be more susceptible to failure in the face of competition (Palmer, 2004; Sagata \& Lester, 2009). Time-lags in density-dependent populations could also explain the population boom of an invasive species followed by a collapse (Strayer et al., 2017). A better understanding of the population dynamics of $P$. dominula is needed moving forward. The continuation of the annual butterfly survey could prove to be a useful indicator of how populations of $P$. dominula change over time. If populations of this invader are beginning to decline, we need to discover the driver to further promote this decrease in numbers. In the absence of any conclusionary evidence that $P$. dominula populations are declining, more pro-active methods for population control need to be explored by biodiversity managers.

New Zealand's ecosystems and economy are under increasing pressure from invasive organisms. The control of invasive species is most effective in the early stages of invasion before the population grows and spreads (Burgos-Rodríguez \& Burgiel, 2019; Simberloff, 2003). Whilst complete eradication of $P$. dominula may not be possible, control of wasp populations will limit the damage inflicted by these predators and may prevent some invertebrate species from becoming locally extinct. Insecticides are commonly utilized for the control of invasive insects (Mack et al., 2000; van Zyl et al., 2018). The diet of $P$. dominula includes protein and carbohydrate-based foods, which are two possible attractants to be used in the development of toxic baits. Carbohydrate-based baits for the control of $P$. dominula are not an option in New 
Zealand as these toxic baits could be attractive to non-target species such as native birds, lizards and honeybees. The protein-based bait, Vespex®, was developed in New Zealand for the control of invasive Vespula wasps and is quite effective in wasp control (Edwards et al., 2017; Lester \& Beggs, 2019). Vespex® attracts foraging Vespula workers that take the bait back to their nests and feed to their nestmates, brood and queen. Based on the foraging behaviour I observed whilst conducting my experiments, control of $P$. dominula using a protein-based bait like Vespex® is not a viable option. To be effective, a bait must be attractive to the target wasp species and be ingested by enough individuals to ensure colony failure. During the monarch caterpillar experiment, individual wasps seemed unable to detect the presence of a caterpillar unless they were in very close proximity. There was also no recruitment of nestmates to a site where a caterpillar had been killed. Unlike Vespula spp., P. dominula only consumes live prey and does not scavenge off dead animals (Beggs et al., 2011). In addition to this, female workers of $P$. dominula are capable of reproduction if the queen dies (Liebig et al., 2005), therefore a large number of nestmates would need to be poisoned for the colony to fail. With all these factors considered, currently produced protein-based baits for $P$. dominula are likely to be ineffective. It is, however, possible that pheromones or other attractants may be utilized in the development of a control, as certain chemicals have been found to attract P. dominula (Landolt \& Zhang, 2016; Landolt et al., 2014).

Continuous improvement to existing pest management strategies and novel control methods are required to limit the effects of invasive organisms. With the increase in tolerance to insecticides in addition to the potential risks to the environment and nontarget species (Chagnon et al., 2015; Relyea, 2005), pest management is moving away from the use of chemicals towards more species-specific control methods (van Zyl et al., 2018). Gene silencing or RNA interference (RNAi) technology is currently being investigated as a control method for a variety of pest organisms (Huvenne \& Smagghe, 2010; Joga et al., 2016; Scott et al., 2013) and has been proven to increase the mortality rate of target insects (Hunter et al., 2012; Zhu et al., 2011). As this technique has a high specificity, there is less risk of non-target species being affected. Further research into novel control methods such as RNAi for the control of $P$. dominula would be valuable as there is potential for effective control of this pest with minimal adverse consequences for New Zealand's ecosystems. If these gene 
silencing techniques prove successful, they have implications not only for $P$. dominula, but also for the control of other invasive insects. 


\section{Appendices}

\section{Appendix A: Nest substrates of Polistes spp. and additional data regarding the nest translocation experiment in chapter two}

Table A1. Manmade nest substrates of $P$. dominula and $P$. chinensis nests monitored over two nesting seasons (2018/19 and 2019/20) in Nelson, New Zealand. The number of nests found on each surface type for both Polistes species are listed. Note: nests built on natural plant surfaces within plant protectors were still considered to be manmade substrates as these locations provided artificial protection from the weather.

\begin{tabular}{|c|c|c|c|}
\hline \multicolumn{4}{|c|}{ Manmade substrate } \\
\hline & Nest surface & P. dominula & P. chinensis \\
\hline \multirow{14}{*}{ Plant protector } & Plastic & 27 & 11 \\
\hline & Leptospermum scoparium & 21 & 6 \\
\hline & Bamboo stick & 15 & 16 \\
\hline & Myoporum laetum & 6 & 16 \\
\hline & Podocarpus totara & 5 & 2 \\
\hline & Linum sp. & 4 & 1 \\
\hline & Plagianthus divaricatus & 4 & 0 \\
\hline & Carex sp. & 3 & 0 \\
\hline & Muehlenbeckia sp. & 2 & 0 \\
\hline & Dead plant & 1 & 2 \\
\hline & Dodonaea viscosa & 1 & 0 \\
\hline & Pittosporum tenuifolium & 1 & 0 \\
\hline & Coprosma repens & 0 & 2 \\
\hline & Fuscospora solandrei & 0 & 1 \\
\hline \multirow[t]{3}{*}{ Fence } & Wood & 18 & 18 \\
\hline & Metal & 9 & 0 \\
\hline & Brick & 0 & 2 \\
\hline \multirow[t]{5}{*}{ House } & Metal & 31 & 0 \\
\hline & Plasterboard & 5 & 0 \\
\hline & Wood & 1 & 2 \\
\hline & Brick & 0 & 2 \\
\hline & Concrete & 0 & 1 \\
\hline \multirow[t]{3}{*}{ Shed } & Metal & 10 & 0 \\
\hline & Wood & 8 & 3 \\
\hline & Plasterboard & 1 & 0 \\
\hline \multirow[t]{4}{*}{ Wall } & Wood & 7 & 0 \\
\hline & Concrete & 5 & 0 \\
\hline & Plastic & 1 & 0 \\
\hline & Rock & 0 & 7 \\
\hline Decking & Wood & 4 & 0 \\
\hline Glasshouse & Metal & 3 & 0 \\
\hline Outdoor furniture & Wood & 3 & 0 \\
\hline Sign & Wood & 3 & 0 \\
\hline Headstone & Concrete & 2 & 1 \\
\hline Mailbox & Metal & 1 & 0 \\
\hline Wheelbarrow & Metal & 1 & 0 \\
\hline Bottle & Plastic & 1 & 0 \\
\hline Pot & Plastic & 0 & 1 \\
\hline Stake & Plastic & 0 & 1 \\
\hline
\end{tabular}


Table A2. Natural nest substrates of $P$. dominula and $P$. chinensis nests monitored over two nesting seasons (2018/19 and 2019/20) in Nelson, New Zealand. The number of nests found on each surface type for both Polistes species are listed.

\begin{tabular}{|c|c|c|c|}
\hline \multicolumn{4}{|c|}{ Natural substrate } \\
\hline & Nest surface & P. dominula & P. chinensis \\
\hline \multirow[t]{25}{*}{ Shrub } & Plagianthus divaricatus & 12 & 93 \\
\hline & Pittosporum tenuifolium & 12 & 5 \\
\hline & Coprosmasp. & 9 & 13 \\
\hline & Leptospermum scoparium & 7 & 11 \\
\hline & Coprosma repens & 5 & 0 \\
\hline & Pittosporum sp. & 3 & 17 \\
\hline & Myoporum laetum & 2 & 2 \\
\hline & Ozothamnus leptophyllus & 2 & 2 \\
\hline & Dodonaea viscosa & 1 & 1 \\
\hline & Podocarpus totara & 1 & 1 \\
\hline & Hebe sp. & 1 & 1 \\
\hline & Sophora sp. & 1 & 0 \\
\hline & Dead plant & 0 & 6 \\
\hline & Myrsine australis & 0 & 3 \\
\hline & Genista sp. & 0 & 2 \\
\hline & Muehlenbechier sp. & 0 & 2 \\
\hline & Abelia sp. & 0 & 2 \\
\hline & Buxus sp. & 0 & 2 \\
\hline & Corokia cotoneaster & 0 & 2 \\
\hline & Hippophae sp. & 0 & 1 \\
\hline & Kunzea ericoides & 0 & 1 \\
\hline & Nepeta sp. & 0 & 1 \\
\hline & Thymus vulgaris & 0 & 1 \\
\hline & Erica oatseii & 0 & 1 \\
\hline & Griselinia littoralis & 0 & 1 \\
\hline \multirow[t]{3}{*}{ Herb } & Lavandula sp. & 0 & 1 \\
\hline & Rumex sp. & 0 & 1 \\
\hline & Iris sp. & 0 & 3 \\
\hline Sedge & Carex sp. & 1 & 18 \\
\hline Rockface & Rock & 1 & 4 \\
\hline Succulent & Aloe vera & 0 & 3 \\
\hline Grass & Uncinia uncinata & 0 & 2 \\
\hline
\end{tabular}


Fig. A1. Proportion of hours where the temperature $\geq 20^{\circ} \mathrm{C}$ $( \pm 95 \% \mathrm{Cl})$ over the 28-day trial period of the $P$. dominula nest translocation experiment within each habitat type. The proportion of hours were found to differ significantly between all three habitat types (Post Hoc Chi-squared test, $P<$ 0.05).

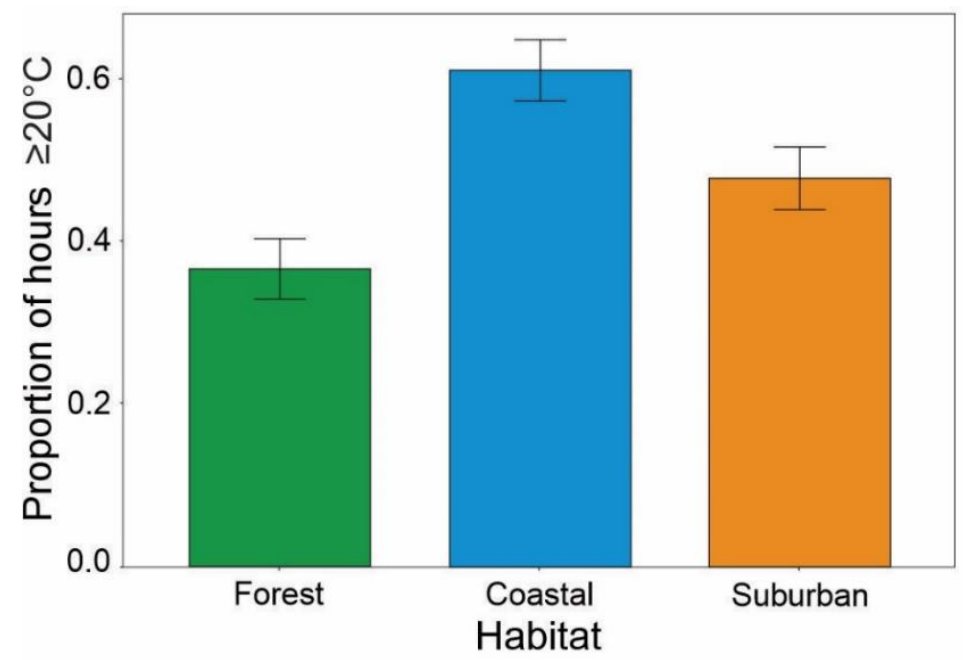

Table A3. Raw data for the $P$. dominula nest translocation experiment, including the initial number of wasps per nest, initial number of cells per nest, final number of wasps, final number of cells and whether the nest survived. Experiment conducted from January $24^{\text {th }}$ until February $20^{\text {th }}, 2020$ in Nelson, New Zealand.

\begin{tabular}{|ll|r|r|r|r|r|l|l|}
\hline Habitat & Nest & $\begin{array}{l}\text { Initial } \\
\text { wasps per } \\
\text { nest }\end{array}$ & $\begin{array}{l}\text { Initial nest } \\
\text { size (\# of } \\
\text { cells) }\end{array}$ & $\begin{array}{l}\text { linal } \\
\text { wasps } \\
\text { per nest }\end{array}$ & $\begin{array}{l}\text { Final } \\
\text { nest size }\end{array}$ & $\begin{array}{l}\text { Change in } \\
\text { wasps per } \\
\text { nest }\end{array}$ & $\begin{array}{l}\text { Change } \\
\text { in nest } \\
\text { size }\end{array}$ & $\begin{array}{l}\text { Nest } \\
\text { survival }\end{array}$ \\
\hline Coastal 1 & D2 & 1 & 50 & 6 & 50 & 5 & 0 & Survived \\
Coastal 1 & D3 & 11 & 54 & 10 & 65 & -1 & 11 & Survived \\
Coastal 1 & D4 & 4 & 47 & 11 & 62 & 6 & 15 & Survived \\
Coastal 1 & D7 & 8 & 55 & 9 & 56 & 1 & 1 & Survived \\
Coastal 2 & D17 & 1 & 42 & 2 & 42 & 1 & 0 & Survived \\
Coastal 2 & D20 & 3 & 33 & 6 & 41 & 3 & 8 & Survived \\
Coastal 2 & D25 & 14 & 77 & 28 & 93 & 14 & 16 & Survived \\
Coastal 2 & D26 & 5 & 43 & 5 & 45 & 0 & 2 & Survived \\
Suburban 1 & D12 & 4 & 63 & 17 & 93 & 13 & 30 & Survived \\
Suburban 1 & D14 & 5 & 59 & 12 & 62 & 7 & 3 & Survived \\
Suburban 1 & D21 & 9 & 65 & 0 & 65 & -9 & 0 & Died \\
Suburban 1 & D24 & 11 & 66 & 21 & 96 & 10 & 30 & Survived \\
Suburban 2 & D8 & 4 & 40 & 0 & 40 & -4 & 0 & Died \\
Suburban 2 & D9 & 6 & 47 & 10 & 54 & 4 & 7 & Survived \\
Suburban 2 & D10 & 5 & 68 & 8 & 70 & 3 & 2 & Survived \\
Suburban 2 & D22 & 14 & 85 & 25 & 98 & 11 & 13 & Survived \\
Forest 1 & D1 & 2 & 60 & 0 & 60 & -2 & 0 & Died \\
Forest 1 & D5 & 4 & 54 & 3 & 54 & -1 & 0 & Survived \\
Forest 1 & D6 & 1 & 54 & 0 & 54 & -1 & 0 & Died \\
Forest 1 & D11 & 3 & 35 & 0 & 35 & -3 & 0 & Died \\
Forest 2 & D13 & 29 & 142 & 21 & 142 & -8 & 0 & Survived \\
Forest 2 & D16 & 8 & 78 & 20 & 78 & 12 & 0 & Survived \\
Forest 2 & D18 & 2 & 70 & 9 & 71 & 7 & 1 & Survived \\
Forest 2 & D23 & 5 & 36 & 0 & 36 & -5 & 0 & Died \\
\hline
\end{tabular}




\section{Appendix B: Climatic data for annual butterfly survey and wasp abundance for chapter three}

Testing the effect of climate on butterfly abundance in Nelson

To investigate the possible effects of climate on butterfly abundance in Nelson, data were used from the National Climate Database using 'CliFlo'. Total rainfall (cm) and average air temperature $\left({ }^{\circ} \mathrm{C}\right)$ data were extracted and have been presented alongside annual averages of butterfly abundance for each species in Table B1. Alongside average butterfly counts, monthly climatic changes have also been plotted for total rainfall $(\mathrm{cm})$ (Fig. B1) and average air temperature $\left({ }^{\circ} \mathrm{C}\right)($ Fig. B2). To discover if there has been a significant change in rainfall or temperature over the summer months in Nelson since 2014 that could explain the decline in butterfly abundance, climatic data were grouped into two time periods: 2009-2014, and 2015-2019. An ANOVA found neither total rainfall nor average air temperature differed significantly between the two periods (Table B2). 
Table B1. Table presenting the average butterfly abundance for the summer that year, alongside total summer rainfall $(\mathrm{cm})$, average summer air temperature $\left({ }^{\circ} \mathrm{C}\right)$, yearly rainfall $(\mathrm{cm})$ and yearly average temperature $\left({ }^{\circ} \mathrm{C}\right)$ for Nelson, New Zealand. Climate data sourced from NIWA (2020) The National Climate Database, New Zealand. https://cliflo.niwa.co.nz

\begin{tabular}{|c|c|c|c|c|c|c|}
\hline & Year & $\begin{array}{c}\text { Ave. butterfly } \\
\text { no. } \\
\end{array}$ & $\begin{array}{c}\text { Total summer } \\
\text { rainfall }(\mathrm{cm})\end{array}$ & $\begin{array}{l}\text { Ave. summer } \\
\text { air temp. }\left({ }^{\circ} \mathrm{C}\right)\end{array}$ & $\begin{array}{c}\text { Yearly } \\
\text { rainfall }(\mathrm{cm})\end{array}$ & $\begin{array}{l}\text { Yearly ave } \\
\text { temp. }\left({ }^{\circ} \mathrm{C}\right)\end{array}$ \\
\hline \multirow[t]{11}{*}{ D. plexippus } & 2009 & 11.1 & 21.1 & 17.4 & 78.3 & 12.5 \\
\hline & 2010 & 28.0 & 31.7 & 18.0 & 96.7 & 13.5 \\
\hline & 2011 & 18.8 & 60.8 & 16.8 & 133.5 & 13.3 \\
\hline & 2012 & 38.6 & 26.4 & 17.7 & 83.7 & 13.0 \\
\hline & 2013 & 28.8 & 27.5 & 17.2 & 98.9 & 13.9 \\
\hline & 2014 & 10.4 & 22.6 & 18.0 & 86.1 & 13.3 \\
\hline & 2015 & 4.3 & 41.2 & 18.5 & 68.4 & 13.3 \\
\hline & 2016 & 5.2 & 27 & 17.3 & 125 & 13.8 \\
\hline & 2017 & 6.6 & 62.3 & 19.2 & 101.9 & 13.7 \\
\hline & 2018 & 7.8 & 20.8 & 18.8 & 129.8 & 13.7 \\
\hline & 2019 & 12.7 & 22.8 & 17.4 & 101.3 & 13.6 \\
\hline \multirow[t]{11}{*}{ P. rapae } & 2009 & 47.8 & 21.1 & 17.4 & 78.3 & 12.5 \\
\hline & 2010 & 71.4 & 31.7 & 18.0 & 96.7 & 13.5 \\
\hline & 2011 & 62.2 & 60.8 & 16.8 & 133.5 & 13.3 \\
\hline & 2012 & 55.1 & 26.4 & 17.7 & 83.7 & 13.0 \\
\hline & 2013 & 64.6 & 27.5 & 17.2 & 98.9 & 13.9 \\
\hline & 2014 & 44.0 & 22.6 & 18.0 & 86.1 & 13.3 \\
\hline & 2015 & 27.1 & 41.2 & 18.5 & 68.4 & 13.3 \\
\hline & 2016 & 21.0 & 27 & 17.3 & 125 & 13.8 \\
\hline & 2017 & 25.3 & 62.3 & 19.2 & 101.9 & 13.7 \\
\hline & 2018 & 25.4 & 20.8 & 18.8 & 129.8 & 13.7 \\
\hline & 2019 & 30.1 & 22.8 & 17.4 & 101.3 & 13.6 \\
\hline \multirow[t]{11}{*}{ Z. labradus } & 2009 & 10.2 & 21.1 & 17.4 & 78.3 & 12.5 \\
\hline & 2010 & 14.5 & 31.7 & 18.0 & 96.7 & 13.5 \\
\hline & 2011 & 2.5 & 60.8 & 16.8 & 133.5 & 13.3 \\
\hline & 2012 & 28.6 & 26.4 & 17.7 & 83.7 & 13.0 \\
\hline & 2013 & 6.9 & 27.5 & 17.2 & 98.9 & 13.9 \\
\hline & 2014 & 14.7 & 22.6 & 18.0 & 86.1 & 13.3 \\
\hline & 2015 & 5.7 & 41.2 & 18.5 & 68.4 & 13.3 \\
\hline & 2016 & 0.3 & 27 & 17.3 & 125 & 13.8 \\
\hline & 2017 & 0.8 & 62.3 & 19.2 & 101.9 & 13.7 \\
\hline & 2018 & 1.5 & 20.8 & 18.8 & 129.8 & 13.7 \\
\hline & 2019 & 0.8 & 22.8 & 17.4 & 101.3 & 13.6 \\
\hline
\end{tabular}


(a)

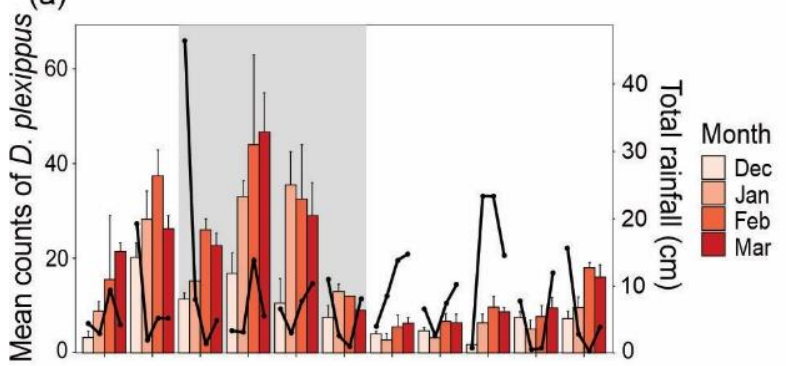

(b)

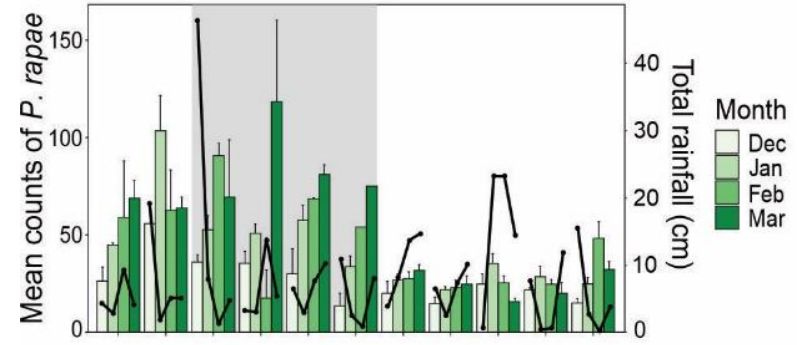

(c)

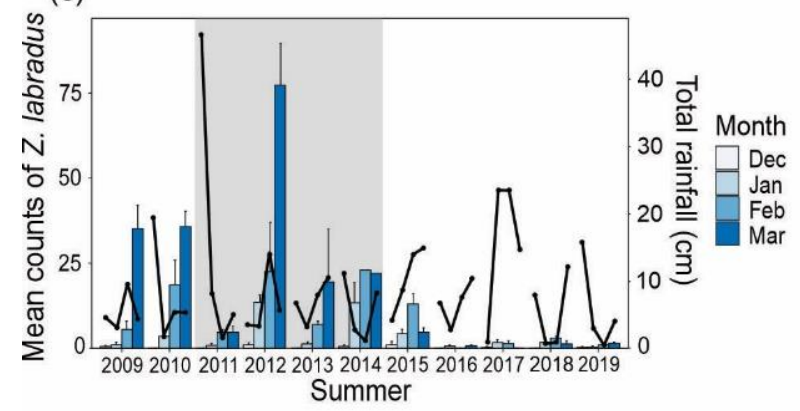

Fig. B1. Data from an annual survey in Nelson showing mean (+ $1 \mathrm{SE}$ ) butterfly abundance and total rainfall $(\mathrm{cm})$ for three local species: (a) $D$. plexippus, (b) P. rapae and (c) Z. labradus. (a)

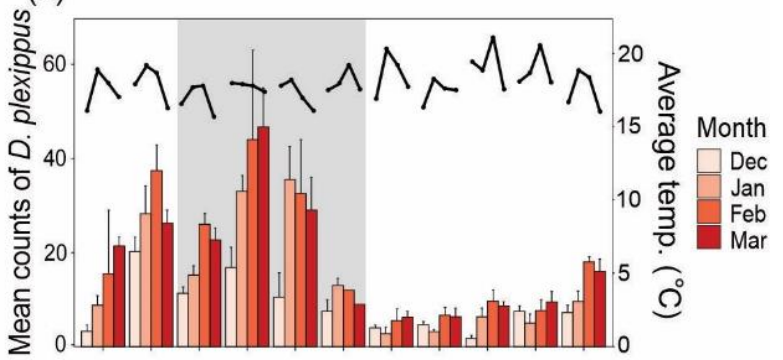

(b)

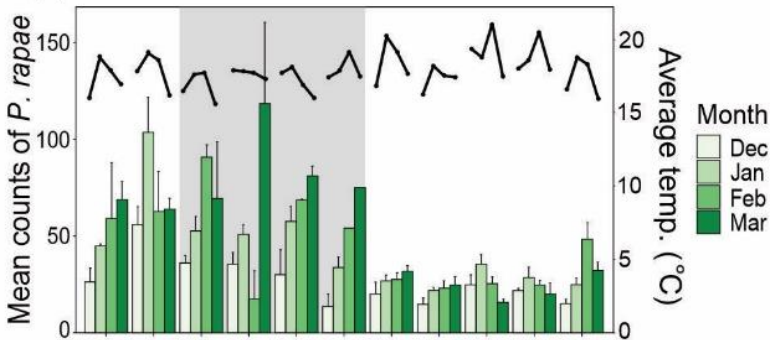

(c)

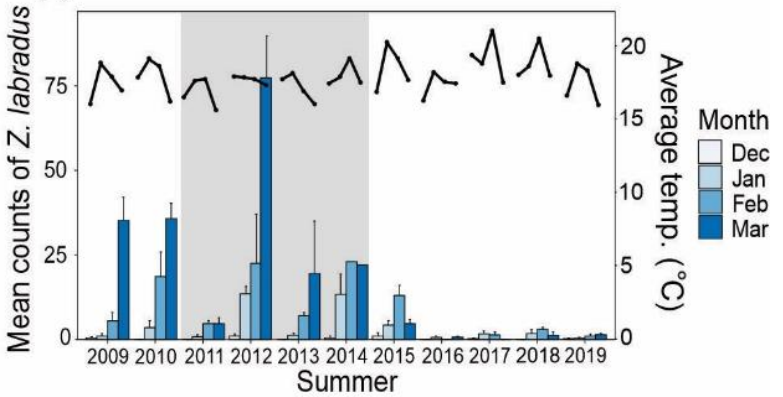

Fig. B2. Data from an annual survey in Nelson showing mean (+ $1 \mathrm{SE}$ ) butterfly abundance and average air temperature $\left({ }^{\circ} \mathrm{C}\right)$ for three local species: (a) D. plexippus, (b) $P$. rapae and (c) Z. labradus.

Table B2. Table presenting the results of an ANOVA investigating the difference in total rainfall $(\mathrm{cm})$ or average air temperatures $\left({ }^{\circ} \mathrm{C}\right)$ for the months of Dec-Mar between the years 2009-2014 and 2015-2019 in Nelson. These time periods correspond to before and after the introduction of $P$. dominula into this region. The ANOVAs were conducted to test if climate variables could be associated with changes in butterfly abundance.

\begin{tabular}{|l|l|l|l|l|l|}
\hline & & df & SS & $F$ & P \\
\hline Total rainfall for Dec-Mar: & Group & 1 & 2678 & 0.11 & 0.753 \\
\hline & Residuals & 9 & 228399 & & \\
\hline Average air temp for Dec-Mar: & Group & 1 & 1.49 & 3.37 & 0.199 \\
\hline & Residuals & 9 & 3.97 & & \\
\hline
\end{tabular}


Table B3. Number of wasps and nests (per $1,000 \mathrm{~m}^{2}$ ) for $P$. dominula and $P$. chinensis at each site during Trial 1 and Trial 2 of the experiment investigating the predation of monarch caterpillars in Nelson, New Zealand.

\begin{tabular}{|llcccc|}
\hline Trial & Site & $\begin{array}{c}\text { P. dominula wasps } \\
\left(1,000 \mathrm{~m}^{2}\right)\end{array}$ & $\begin{array}{c}\text { P. chinensis } \\
\text { wasps }\left(1,000 \mathrm{~m}^{2}\right)\end{array}$ & $\begin{array}{c}P . \text { dominula nests } \\
\left(1,000 \mathrm{~m}^{2}\right)\end{array}$ & $\begin{array}{c}\text { P. chinensis nests } \\
\left(1,000 \mathrm{~m}^{2}\right)\end{array}$ \\
& Suburban 1 & 91 & 2 & 12 & 1 \\
& Forest 1 & 0 & 0 & 0 & 0 \\
& Coastal 1 & 122 & 25 & 6 & 2 \\
& Suburban 2 & 114 & 2 & 13 & 1 \\
& Forest 2 & 0 & 0 & 0 & 0 \\
Trial & Coastal 2 & 1 & 18 & 1 & 2 \\
2 & Suburban 1 & 99 & 3 & 11 & 1 \\
& Forest 1 & 0 & 0 & 0 & 0 \\
& Coastal 1 & 129 & 29 & 5 & 2 \\
& Suburban 2 & 139 & 3 & 12 & 1 \\
& Forest 2 & 0 & 0 & 0 & 0 \\
& Coastal 2 & 1 & 26 & 1 & 2 \\
\hline
\end{tabular}




\section{References}

Ali, A., Desneux, N., Lu, Y.H., \& Wu, K.M. (2018) Key aphid natural enemies showing positive effects on wheat yield through biocontrol services in northern China. Agriculture Ecosystems \& Environment, 266, 1-9.

Armstrong, T.R. \& Stamp, N.E. (2003) Colony productivity and foundress behaviour of a native wasp versus an invasive social wasp. Ecological Entomology, 28, 635-644.

Baker, A.M. \& Potter, D.A. (2020) Invasive paper wasp turns urban pollinator gardens into ecological traps for monarch butterfly larvae. Scientific Reports, 10, 1-7.

Bamber, J.A., Shuttleworth, C.M., Hayward, M.W., \& Everest, D.J. (2020) Reinstating trophic cascades as an applied conservation tool to protect forest ecosystems from invasive grey squirrels (Sciurus carolinensis). Food Webs, 25, 2352-2496.

Bates, D., Mächler, M., Bolker, B., \& Walker, S. (2014) Fitting linear mixed-effects models using Ime4. Journal of Statistical Software, 67, 1-48.

Beggs, J.R., Brockerhoff, E.G., Corley, J.C., Kenis, M., Masciocchi, M., Muller, F., Rome, Q., \& Villemant, C. (2011) Ecological effects and management of invasive alien Vespidae. Biocontrol, 56, 505-526.

Beggs, J.R. \& Rees, J.S. (1999) Restructuring of Lepidoptera communities by introduced Vespula wasps in a New Zealand beech forest. Oecologia, 119, 565-571.

Benade, P.C., Veldtman, R., Samways, M.J., \& Roets, F. (2014) Rapid range expansion of the invasive wasp Polistes dominula (Hymenoptera: Vespidae: Polistinae) and first record of parasitoids on this species and the native Polistes marginalis in the Western Cape province of South Africa. African Entomology, 22, 220-225.

Beschta, R.L. \& Ripple, W.J. (2009) Large predators and trophic cascades in terrestrial ecosystems of the western United States. Biological Conservation, 142, 2401-2414.

Borer, E.T., Halpern, B.S., \& Seabloom, E.W. (2006) Asymmetry in community regulation: effects of predators and productivity. Ecology, 87, 2813-2820.

Bradley, B.A., Laginhas, B.B., Whitlock, R., Allen, J.M., Bates, A.E., Bernatchez, G., Diez, J.M., Early, R., Lenoir, J., Vila, M., \& Sorte, C.J.B. (2019) Disentangling the abundance-impact relationship for invasive species. Proceedings of the National Academy of Sciences of the United States of America, 116, 9919-9924.

Brenton-Rule, E., Frankel, S., \& Lester, P. (2016) Improving management of invasive species: New Zealand's approach to pre- and post-border pests. Policy Quaterly, 12, 17-25.

Britten, G.L., Dowd, M., Minto, C., Ferretti, F., Boero, F., \& Lotze, H.K. (2014) Predator decline leads to decreased stability in a coastal fish community. Ecology letters, 17, 1518-1525.

Brockerhoff, E., Barratt, B.I.P., Beggs, Jr., Fagan, L., Kay, M., Phillips, C., \& Vink, C.J. (2010) Impacts of exotic invertebrates on New Zealand's indigenous species and ecosystems. New Zealand Journal of Ecology, 34, 158-174.

Burgos-Rodríguez, J. \& Burgiel, S.W. (2019) Federal legal authorities for the early detection of and rapid response to invasive species. Biological Invasions, 22, 129-146.

Caesar, A. (2005) Melding ecology, classical weed biocontrol, and plant microbial ecology can inform improved practices in controlling invasive plant species. Biological control, 35, 240-246.

Cassey, P. (2001) Determining variation in the success of New Zealand land birds. Global Ecology and Biogeography, 10, 161-172.

Cervo, R., Zacchi, F., \& Turillazzi, S. (2000) Polistes dominulus (Hymenoptera, Vespidae) invading North America: some hypotheses for its rapid spread. Insectes Sociaux, 47, 155-157.

Chagnon, M., Kreutzweiser, D., Mitchell, E.A., Morrissey, C.A., Noome, D.A., \& Van der Sluijs, J.P. (2015) Risks of large-scale use of systemic insecticides to ecosystem functioning and services. Environmental Science and Pollution Research, 22, 119-134.

Clapperton, B., Tilley, J., \& Pierce, R. (1996) Distribution and abundance of the Asian paper wasp Polistes chinensis antennalis Perez and the Australian paper wasp P. humilis (Fab.)(Hymenoptera: Vespidae) in New Zealand. New Zealand Journal of Zoology, 23, 19-25.

Clapperton, B.K. (1999) Abundance of wasps and prey consumption of paper wasps (Hymenoptera, Vespidae: Polistinae) in Northland, New Zealand. New Zealand Journal of Ecology, 23, 11-19. 
Clapperton, B.K. \& Dymock, J.J. (1997) Growth and survival of colonies of the Asian paper wasp, Polistes chinensis antennalis (Hymenoptera: Vespidae), in New Zealand. New Zealand Journal of Zoology, 24, 9-15.

Clapperton, B.K. \& Lo, P.L. (2000) Nesting biology of Asian paper wasps Polistes chinensis antennalis Perez, and Australian paper wasps $P$. humilis (Fab.)(Hymenoptera: Vespidae) in northern New Zealand. New Zealand Journal of Zoology, 27, 189-195.

Clark, J.A. \& May, R.M. (2002) Taxonomic bias in conservation research. Science, 297, 191-193.

Cooling, M., Hartley, S., Sim, D.A., \& Lester, P.J. (2012) The widespread collapse of an invasive species: Argentine ants (Linepithema humile) in New Zealand. Biology Letters, 8, 430-433.

Cooling, M. \& Hoffmann, B.D. (2015) Here today, gone tomorrow: declines and local extinctions of invasive ant populations in the absence of intervention. Biological Invasions, 17, 3351-3357.

Cranshaw, W.S., Larsen, H.J., \& Zimmerman, R.J. (2011) Notes on fruit damage by the European paper wasp, Polistes dominula (Christ) (Hymenoptera: Vespidae). Southwestern Entomologist, 36, 103-105.

Crowder, D.W. \& Snyder, W.E. (2010) Eating their way to the top? Mechanisms underlying the success of invasive insect generalist predators. Biological Invasions, 12, 2857-2876.

Detoni, M., Barbosa, B.C., Maciel, T.T., dos Santos, S.J.L., \& Prezoto, F. (2018) Long- and short-term changes in social wasp community structure in an urban area. Sociobiology, 65, 305-311.

Dew, H.E. \& Michener, C.D. (1978) Foraging flights of two species of Polistes wasps (Hymenoptera: Vespidae). Journal of the Kansas Entomological Society, 51, 380-385.

Dixon, P. (2003) VEGAN, a package of R functions for community ecology. Journal of Vegetation Science, 14, 927-930.

Donlan, C.J. \& Wilcox, C. (2008) Diversity, invasive species and extinctions in insular ecosystems. Journal of Applied Ecology, 1114-1123.

Dowding, J.E. \& Murphy, E.C. (2001) The impact of predation by introduced mammals on endemic shorebirds in New Zealand: a conservation perspective. Biological Conservation, 99, 47-64.

Edwards, E., Toft, R., Joice, N., \& Westbrooke, I. (2017) The efficacy of Vespex ${ }^{\circledR}$ wasp bait to control Vespula species (Hymenoptera: Vespidae) in New Zealand. International Journal of Pest Management, 63, 266272.

Flory, S.L., Kleczewski, N., \& Clay, K. (2011) Ecological consequences of pathogen accumulation on an invasive grass. Ecosphere, 2, 1-12.

Gamboa, G., Noble, M., Thom, M., Togal, J., Srinivasan, R., \& Murphy, B. (2004) The comparative biology of two sympatric paper wasps in Michigan, the native Polistes fuscatus and the invasive Polistes dominulus (Hymenoptera, Vespidae). Insectes Sociaux, 51, 153-157.

Gamboa, G.J., Austin, J.A., \& Monnet, K.M. (2005) Effects of different habitats on the productivity of the native paper wasp Polistes fuscatus and the invasive, exotic paper wasp P. dominulus (Hymenoptera: Vespidae). Great Lakes Entomologist, 38, 170-176.

Gibbs, G.W. (1980) New Zealand butterflies: Identification and natural history, Collins, Auckland, New Zealand.

Gould, W.P. \& Jeanne, R. (1984) Polistes wasps (Hymenoptera: Vespidae) as control agents for Lepidopterous cabbage pests. Environmental Entomology, 13, 150-156.

Grinsted, L. \& Field, J. (2018) Predictors of nest growth: diminishing returns for subordinates in the paper wasp Polistes dominula. Behavioral Ecology and Sociobiology, 72, 1-8.

Gurevitch, J. \& Padilla, D.K. (2004) Are invasive species a major cause of extinctions? Trends in Ecology \& Evolution, 19, 470-474.

Halaj, J. \& Wise, D.H. (2001) Terrestrial trophic cascades: How much do they trickle? The American Naturalist, 157, 262-281.

Hervé, M. \& Hervé, M.M. (2020) Package 'RVAideMemoire', Version 0.9-78.

Hoare, R.J., Dugdale, J.S., Edwards, E.D., Gibbs, G.W., Patrick, B., Hitchmough, R., \& Rolfe, J.R. (2017) Conservation status of New Zealand butterflies and moths (Lepidoptera), 2015 Publishing Team, Department of Conservation, New Zealand.

Höcherl, N. \& Tautz, J. (2015) Nesting behavior of the paper wasp Polistes dominula in Central Europe-a flexible system for expanding into new areas. Ecosphere, 6, 1-11. 
Holdsworth, M. (1956) The concept of minimum leaf number. Journal of Experimental Botany, 7, 395-409.

Holway, D.A., Lach, L., Suarez, A.V., Tsutsui, N.D., \& Case, T.J. (2002) The causes and consequences of ant invasions. Annual Review of Ecology and Systematics, 33, 181-233.

Howse, M.W.F., Haywood, J., \& Lester, P.J. (2020) Bioclimatic modelling identifies suitable habitat for the establishment of the invasive European paper wasp (Hymenoptera: Vespidae) across the southern hemisphere. Insects, 11, 784.

Howse, M.W.F., McGruddy, R., Haywood, J., Toft, R., \& Lester, P. (2021) Predicted distribution and diet analysis of the invasive paper wasps Polistes dominula in New Zealand [Unpublished master's thesis]. Victoria University of Wellington.

Hozumi, S., Kudo, K., Katakura, H., \& Yamane, S. (2015) Ambient temperature influences geographic changes in nest and colony size of Polistes chinensis antennalis Perez (Hymenoptera: Vespidae). Sociobiology, 62, 88-91.

Hunter, W.B., Glick, E., Paldi, N., \& Bextine, B.R. (2012) Advances in RNA interference: dsRNA treatment in trees and grapevines for insect pest suppression. Southwest Entomologist, 37, 85-87.

Huvenne, H. \& Smagghe, G. (2010) Mechanisms of dsRNA uptake in insects and potential of RNAi for pest control: A review. Journal of Insect Physiology, 56, 227-235.

In, J. \& Lee, D.K. (2019) Survival analysis: part II-applied clinical data analysis. Korean journal of anesthesiology, 72, 441.

Inagawa, K., Kojima, J., Sayama, K., \& Tsuchida, K. (2001) Colony productivity of the paper wasp Polistes snelleni: Comparison between cool-temperate and warm-temperate populations. Insectes Sociaux, 48, 259-265.

Jager, K.J., Van Dijk, P.C., Zoccali, C., \& Dekker, F.W. (2008) The analysis of survival data: the Kaplan-Meier method. Kidney International, 74, 560-565.

Jeanne, R.L., Hunt, J.H., \& Keeping, M.G. (1995) Foraging in social wasps: Agelaia lacks recruitment to food (Hymenoptera: Vespidae). Journal of the Kansas Entomological Society, 68, 279-289.

Jeanne, R.L. \& Morgan, R.C. (1992) The influence of temperature on nest site choice and reproductive strategy in a temperate zone Polistes wasp. Ecological Entomology, 17, 135-141.

Jeon, M.G., Kim, T.G., Jung, J.C., \& Choi, M.B. (2019) Prey diversity of Polistes rothneyi koreanus in different landscapes using DNA barcoding. Journal of Applied Entomology.

Joga, M.R., Zotti, M.J., Smagghe, G., \& Christiaens, O. (2016) RNAi efficiency, systemic properties, and novel delivery methods for pest insect control: what we know so far. Frontiers in Physiology, 7, 1-14.

Kovac, H., Kafer, H., \& Stabentheiner, A. (2019) The thermoregulatory behavior of nectar foraging Polistine wasps (Polistes dominula and Polistes gallicus) in different climate conditions. Insects, 10, 1-9.

Landolt, P. \& Zhang, Q.H. (2016) Discovery and development of chemical attractants used to trap pestiferous social wasps (Hymenoptera: Vespidae). Journal of Chemical Ecology, 42, 655-665.

Landolt, P.J., Cha, D.H., Werle, C.T., Adamczyk, J.J., Meagher, R.L., Gilbride, R.L., Clepper, T.S., Reed, H.C., Teal, P.E.A., \& Sampson, B.J. (2014) Polistes spp. (Hymenoptera: Vespidae) orientation to wine and vinegar. Florida Entomologist, 97, 1620-1630.

Lester, P. (2018) The vulgar wasp: the story of a ruthless invader and ingenious predator Victoria University Press, Wellington, New Zealand.

Lester, P.J. \& Beggs, J.R. (2019) Invasion success and management strategies for social Vespula wasps. Annual Review of Entomology, 64, 51-71.

Lester, P.J. \& Gruber, M.A. (2016) Booms, busts and population collapses in invasive ants. Biological Invasions, 18, 3091-3101.

Liebert, A.E., Gamboa, G.J., Stamp, N.E., Curtis, T.R., Monnet, K.M., Turillazzi, S., \& Starks, P.T. (2006) Genetics, behavior and ecology of a paper wasp invasion: Polistes dominulus in North America. Annales Zoologici Fennici, 43, 595-624.

Liebig, J., Monnin, T., \& Turillazzi, S. (2005) Direct assessment of queen quality and lack of worker suppression in a paper wasp. Proceedings of the Royal Society B: Biological Sciences, 272, 1339-1344. 
Liere, H., Kim, T.N., Werling, B.P., Meehan, T.D., Landis, D.A., \& Gratton, C. (2015) Trophic cascades in agricultural landscapes: indirect effects of landscape composition on crop yield. Ecological Applications, 25, 652-661.

Lin, H. \& Zelterman, D. (2002) Modeling survival data: extending the Cox model. Technometrics, 44, 85-86.

Maclntyre, P. \& Hellstrom, J. (2015). An evaluation of the costs of pest wasps (Vespula species) in New Zealand, Department of Conservation and Ministry for Primary Industries, Wellington, New Zealand.

Mack, R.N., Simberloff, D., Mark Lonsdale, W., Evans, H., Clout, M., \& Bazzaz, F.A. (2000) Biotic invasions: causes, epidemiology, global consequences, and control. Ecological Applications, 10, 689-710.

McGruddy, R.A., Howse, M.W.F., Haywood, J., Ward, C.J.I., Staufer, T.B., Hayek-Williams, M., Toft, R.J., \& Lester, P.J. (2020) Invasive paper wasps have strong cascading effects on the host plant of monarch butterflies. Ecological Entomology, Retrieved from https://doi.org/10.1111/een.12992

Menke, S.B. \& Holway, D.A. (2020) Historical resurvey indicates no decline in Argentine ant site occupancy in coastal southern California. Biological Invasions, 22, 1669-1679.

Miyano, S. (1980) Life tables of colonies and workers in a paper wasp, Polistes Chinensis antennalis, in central Japan (Hymenoptera: Vespidae). Researches on Population Ecology, 22, 69-88.

Moon, D.C. \& Silva, D. (2013) Environmental heterogeneity mediates a cross-ecosystem trophic cascade. Ecological Entomology, 38, 23-30.

Moya-Laraño, J. \& Wise, D.H. (2007) Direct and indirect effects of ants on a forest-floor food web. Ecology, 88, 1454-1465.

MPI (2016) European paper wasp. Ministry for Primary Industries, New Zealand. https://www.pmanz.nz/uploads/5/3/1/0/53106237/european paper wasp fs sept2016 web.pdf [accessed on 5 August 2020].

MPI (2018) Schedule of regulated (quarantine) weed seeds. Ministry for Primary Industries, New Zealand. https://www.biosecurity.govt.nz/dmsdocument/7111/direct [accessed on 16 October 2020].

NIWA (2016) Regional climatologies. National Institute of Water and Atmospheric Research, New Zealand. https://niwa.co.nz/our-science/climate/publications/regional-climatologies [accessed on 25 November 2019].

Nuñez, M.A., Chiuffo, M.C., Torres, A., Paul, T., Dimarco, R.D., Raal, P., Policelli, N., Moyano, J., García, R.A., \& Van Wilgen, B.W. (2017) Ecology and management of invasive Pinaceae around the world: progress and challenges. Biological Invasions, 19, 3099-3120.

O'Dowd, D.J., Green, P.T., \& Lake, P.S. (2003) Invasional 'meltdown'on an oceanic island. Ecology Letters, 6, 812-817.

Paini, D.R., Sheppard, A.W., Cook, D.C., De Barro, P.J., Worner, S.P., \& Thomas, M.B. (2016) Global threat to agriculture from invasive species. Proceedings of the National Academy of Sciences, 113, 7575-7579.

Palmer, T.M. (2004) Wars of attrition: colony size determines competitive outcomes in a guild of African acacia ants. Animal Behaviour, 68, 993-1004.

Paolucci, E.M., Maclsaac, H.J., \& Ricciardi, A. (2013) Origin matters: alien consumers inflict greater damage on prey populations than do native consumers. Diversity and Distributions, 19, 988-995.

Paulay, G. (1994) Biodiversity on oceanic islands: its origin and extinction. American zoologist, 34, 134-144.

Perez-Bote, J.L. \& Mora-Rubio, C. (2020) Causes of Polistes dominula (Christ, 1791) (Hymenoptera, Vespidae) colony mortality in urban areas of the south-western Iberian Peninsula. Graellsia, 76, 1-4.

Perez-Bote, J.L., Mora-Rubio, C., Lopez Martinez, J.L., \& Rodriguez Riano, T.R. (2020) Nesting ecology of Polistes gallicus (Hymenoptera: Vespidae) in South-Western Spain. European Journal of Entomology, 117, 243251.

Pickett, K.M. \& Wenzel, J.W. (2000) High productivity in haplometrotic colonies of the introduced paper wasp Polistes dominulus (Hymenoptera: Vespidae; Polistinae). Journal of the New York Entomological Society, 108, 314-325.

Pilowsky, J.A. \& Starks, P.T. (2018) Displacement and replacement in real time: Polistes dominula's impact on P. fuscatus in the northeastern US. Biological Invasions, 20, 1161-1169.

Piovia-Scott, J., Yang, L.H., \& Wright, A.N. (2017) Temporal variation in trophic cascades. Annual Review of Ecology, Evolution, and Systematics, 48, 281-300. 
Potter-Craven, J., Kirkpatrick, J.B., McQuillan, P.B., \& Bell, P. (2018) The effects of introduced vespid wasps (Vespula germanica and $V$-vulgaris) on threatened native butterfly (Oreixenica ptunarra) populations in Tasmania. Journal of Insect Conservation, 22, 521-532.

Pysek, P., Hulme, P.E., Simberloff, D., Bacher, S., Blackburn, T.M., Carlton, J.T., Dawson, W., Essl, F., Foxcroft, L.C., Genovesi, P., Jeschke, J.M., Kuhn, I., Liebhold, A.M., Mandrak, N.E., Meyerson, L.A., Pauchard, A., Pergl, J., Roy, H.E., Seebens, H., van Kleunen, M., Vila, M., Wingfield, M.J., \& Richardson, D.M. (2020) Scientists' warning on invasive alien species. Biological Reviews, 95, 1511-1534.

Pysek, P. \& Richardson, D.M. (2010) Invasive species, environmental change and management, and health. Annual Review of Environment and Resources, 35, 25-55.

$\mathrm{R}$ Development Core Team. (2020) R: a language and environment for statistical computing. R Foundation for Statistical Computing, Vienna, Austria. https://www.R-project.org.

Rafferty, N.E. \& Ives, A.R. (2012) Pollinator effectiveness varies with experimental shifts in flowering time. Ecology, 93, 803-814.

Rayor, L.S. (2004) Effects of monarch larval host plant chemistry and body size on Polistes wasp predation Cornell University Press, Ithaca, New York.

Reaser, J.K., Meyerson, L.A., Cronk, Q., De Poorter, M., Eldrege, L., Green, E., Kairo, M., Latasi, P., Mack, R.N., \& Mauremootoo, J. (2007) Ecological and socioeconomic impacts of invasive alien species in island ecosystems. Environmental Conservation, 34, 98-111.

Reed, H.C. \& Vinson, S. (1979) Nesting ecology of paper wasps (Polistes) in a Texas urban area (Hymenoptera: Vespidae). Journal of the Kansas Entomological Society, 673-689.

Relva, M.A., Nunez, M.A., \& Simberloff, D. (2010) Introduced deer reduce native plant cover and facilitate invasion of non-native tree species: evidence for invasional meltdown. Biological Invasions, 12, 303311.

Relyea, R.A. (2005) The impact of insecticides and herbicides on the biodiversity and productivity of aquatic communities. Ecological Applications, 15, 618-627.

Renault, D., Laparie, M., McCauley, S.J., \& Bonte, D. (2018) Environmental adaptations, ecological filtering, and dispersal central to insect invasions. Annual Review of Entomology, 63, 345-368.

Richter, M.R. (2000) Social wasp (Hymenoptera: Vespidae) foraging behavior. Annual Review of Entomology, 45, 121.

Ripple, W.J. \& Beschta, R.L. (2012) Trophic cascades in Yellowstone: the first 15 years after wolf reintroduction. Biological Conservation, 145, 205-213.

Ripple, W.J., Estes, J.A., Schmitz, O.J., Constant, V., Kaylor, M.J., Lenz, A., Motley, J.L., Self, K.E., Taylor, D.S., \& Wolf, C. (2016) What is a trophic cascade? Trends in Ecology \& Evolution, 31, 842-849.

Roets, F., Benade, P.C., Samways, M.J., \& Veldtman, R. (2019) Better colony performance, not natural enemy release, explains numerical dominance of the exotic Polistes dominula wasp over a native congener in South Africa. Biological Invasions, 21, 925-933.

Rosumek, F., Silveira, F., S. Neves, F., U. Barbosa, N., Diniz, L., Oki, Y., Pezzini, F., Fernandes, G., \& Cornelissen, T. (2009) Ants on plants: a meta-analysis of the role of ants as plant biotic defenses. Oecologia, 160, 537-549.

Roy, H.E., De Clercq, P., Lawson Handley, L.-J., Poland, R.L., Sloggett, J.J., \& Wajnberg, E. (2011) Alien arthropod predators and parasitoids: an ecological approach. BioControl, 56, 375-382.

Sagata, K. \& Lester, P.J. (2009) Behavioural plasticity associated with propagule size, resources, and the invasion success of the Argentine ant Linepithema humile. Journal of Applied Ecology, 46, 19-27.

Salo, P., Korpimäki, E., Banks, P.B., Nordström, M., \& Dickman, C.R. (2007) Alien predators are more dangerous than native predators to prey populations. Proceedings of the Royal Society B: Biological Sciences, 274, 1237-1243.

Schmack, J., Schleuning, M., Ward, D., \& Beggs, J. (2020) Biogeography and anthropogenic impact shape the success of invasive wasps on New Zealand's offshore islands. Diversity and Distributions, 26, 441-452.

Scott, J.G., Michel, K., Bartholomay, L.C., Siegfried, B.D., Hunter, W.B., Smagghe, G., Zhu, K.Y., \& Douglas, A.E. (2013) Towards the elements of successful insect RNAi. Journal of Insect Physiology, 59, 1212-1221.

Seastedt, T.R. \& Crossley, D.A. (1984) The influence of arthropods on ecosystems. Bioscience, 34, 157-161. 
Shears, N.T. \& Babcock, R.C. (2002) Marine reserves demonstrate top-down control of community structure on temperate reefs. Oecologia, 132, 131-142.

Sheehan, M.J., Botero, C.A., Hendry, T.A., Sedio, B.E., Jandt, J.M., Weiner, S., Toth, A.L., \& Tibbetts, E.A. (2015) Different axes of environmental variation explain the presence vs. extent of cooperative nest founding associations in Polistes paper wasps. Ecology letters, 18, 1057-1067.

Simberloff, D. (2003) Eradication - preventing invasions at the outset. Weed Science, 51, 247-253.

Simberloff, D. \& Gibbons, L. (2004) Now you see them, now you don't!-population crashes of established introduced species. Biological Invasions, 6, 161-172.

Snyder, W.E., Clevenger, G.M., \& Eigenbrode, S.D. (2004) Intraguild predation and successful invasion by introduced ladybird beetles. Oecologia, 140, 559-565.

Snyder, W.E. \& Evans, E.W. (2006) Ecological effects of invasive arthropod generalist predators. Annual Review of Ecology Evolution and Systematics, 37, 95-122.

Sorvari, J. (2018) Habitat preferences and spring temperature-related abundance of German wasp Vespula germanica in its northern range. Insect Conservation and Diversity, 11, 363-369.

Southon, R.J., Fernandes, O.A., Nascimento, F.S., \& Sumner, S. (2019) Social wasps are effective biocontrol agents of key lepidopteran crop pests. Proceedings of the Royal Society $B, 286,1-8$.

Spatz, D.R., Zilliacus, K.M., Holmes, N.D., Butchart, S.H., Genovesi, P., Ceballos, G., Tershy, B.R., \& Croll, D.A. (2017) Globally threatened vertebrates on islands with invasive species. Science Advances, 3, 1-12.

Strayer, D.L., D'Antonio, C.M., Essl, F., Fowler, M.S., Geist, J., Hilt, S., Jarić, I., Jöhnk, K., Jones, C.G., \& Lambin, X. (2017) Boom-bust dynamics in biological invasions: towards an improved application of the concept. Ecology Letters, 20, 1337-1350.

Stringer, I. \& Hitchmough, R. (2012) Assessing the conservation status of New Zealand's native terrestrial invertebrates. New Zealand Entomologist, 35, 77-84.

Sumner, S., Law, G., \& Cini, A. (2018) Why we love bees and hate wasps. Ecological Entomology, 43, 836-845.

Terborgh, J., Lopez, L., Nunez, P., Rao, M., Shahabuddin, G., Orihuela, G., Riveros, M., Ascanio, R., Adler, G.H., Lambert, T.D., \& Balbas, L. (2001) Ecological meltdown in predator-free forest fragments. Science, 294, 1923-1926.

Tibbetts, E.A. \& Dale, J. (2004) A socially enforced signal of quality in a paper wasp. Nature, 432, 218-222.

Tibbetts, E.A. \& Lindsay, R. (2008) Visual signals of status and rival assessment in Polistes dominulus paper wasps. Biology Letters, 4, 237-239.

Tibbetts, E.A. \& Reeve, H.K. (2003) Benefits of foundress associations in the paper wasp Polistes dominulus: increased productivity and survival, but no assurance of fitness returns. Behavioral Ecology, 14, 510514.

Toft, R.J. \& Rees, J.S. (1998) Reducing predation of orb-web spiders by controlling common wasps (Vespula vulgaris) in a New Zealand beech forest. Ecological Entomology, 23, 90-95.

Torchin, M.E., Lafferty, K., D. , Dobson, A., P. , Mckenzie, V., J. , \& Kuris, A., M. (2003) Introduced species and their missing parasites. Nature, 421, 628-630.

Tsutsui, N.D. \& Suarez, A.V. (2003) The colony structure and population biology of invasive ants. Conservation Biology, 17, 48-58.

van Zyl, C., Addison, P., \& Veldtman, R. (2018) The invasive Vespidae in South Africa: potential management strategies and current status. African Entomology, 26, 267-285.

Vilà, M., Espinar, J.L., Hejda, M., Hulme, P.E., Jarošík, V., Maron, J.L., Pergl, J., Schaffner, U., Sun, Y., \& Pyšek, P. (2011) Ecological impacts of invasive alien plants: a meta-analysis of their effects on species, communities and ecosystems. Ecology letters, 14, 702-708.

Ward, D. \& Morgan, F. (2014) Modelling the impacts of an invasive species across landscapes: a step-wise approach. Peerj, 2, 1-14.

Ward, D.F. \& Ramón-Laca, A. (2013) Molecular identification of the prey range of the invasive Asian paper wasp. Ecology and Evolution, 3, 4408-4414.

Waters, J.M. \& Craw, D. (2006) Goodbye Gondwana? New Zealand biogeography, geology, and the problem of circularity. Systematic Biology, 55, 351-356.

Watt, J. (1975). The terrestrial insects. In Biogeography and ecology in New Zealand, pp. 507-535. Springer. 
Weiner, S.A., Noble, K., Upton, C.T., Woods, W.A., \& Starks, P.T. (2011) A role for thermoregulation in the Polistes dominulus invasion: a comparison of the thermoregulatory abilities of the invasive wasp $P$. dominulus and the native wasp P. fuscatus. Insectes Sociaux, 58, 185-190.

Wetterer, J.K., Davis, O., \& Williamson, J.R. (2014) Boom and bust of the tawny crazy ant, Nylanderia fulva (Hymenoptera: Formicidae), on St. Croix, US Virgin Islands. Florida Entomologist, 97, 1099-1103.

Wilson, K.-J. (1997) Extinct and introduced vertebrate species in New Zealand: a loss of biodistinctiveness and gain in biodiversity. Pacific Conservation Biology, 3, 301-305.

Wise, K. (1980) Monarch butterfly dispersal in New Zealand. Auckland War Memorial Museum, 17, 157-173.

Worm, B. \& Myers, R.A. (2003) Meta-analysis of cod-shrimp interactions reveals top-down control in oceanic food webs. Ecology, 84, 162-173.

Zalucki, M.P. \& Clarke, A.R. (2004) Monarchs across the Pacific: the Columbus hypothesis revisited. Biological Journal of the Linnean Society, 82, 111-121.

Zavaleta, E.S., Hobbs, R.J., \& Mooney, H.A. (2001) Viewing invasive species removal in a whole-ecosystem context. Trends in Ecology and Evolution, 16, 454-459.

Zhu, F., Xu, J., Palli, R., Ferguson, J., \& Palli, S.R. (2011) Ingested RNA interference for managing the populations of the Colorado potato beetle, Leptinotarsa decemlineata. Pest Management Science, 67, 175-182. 